\title{
Spiers Memorial Lecture: Coordination networks that switch between nonporous and porous structures: an emerging class of soft porous crystals
}

\author{
Shi-Qiang Wang, (D) a Soumya Mukherjee (iD ab \\ and Michael J. Zaworotko (iD *a
}

\section{Received 1st June 2021, Accepted 14th June 2021 \\ DOI: $10.1039 / \mathrm{d} 1 \mathrm{fd} 00037 \mathrm{c}$}

Coordination networks (CNs) are a class of (usually) crystalline solids typically comprised of metal ions or cluster nodes linked into 2 or 3 dimensions by organic and/or inorganic linker ligands. Whereas $\mathrm{CNs}$ tend to exhibit rigid structures and permanent porosity as exemplified by most metal-organic frameworks, MOFs, there exists a small but growing class of $\mathrm{CNs}$ that can undergo extreme, reversible structural transformation(s) when exposed to gases, vapours or liquids. These "soft" or "stimuli-responsive" CNs were introduced two decades ago and are attracting increasing attention thanks to two features: the amenability of $\mathrm{CNs}$ to design from first principles, thereby enabling crystal engineering of families of related $\mathrm{CNs}$; and the potential utility of soft $\mathrm{CNs}$ for adsorptive storage and separation. A small but growing subset of soft CNs exhibit reversible phase transformations between nonporous (closed) and porous (open) structures. These "switching CNs" are distinguished by stepped sorption isotherms coincident with phase transformation and, perhaps counterintuitively, they can exhibit benchmark properties with respect to working capacity (storage) and selectivity (separation). This review addresses fundamental and applied aspects of switching CNs through surveying their sorption properties, analysing the structural transformations that enable switching, discussing structure-function relationships and presenting design principles for crystal engineering of the next generation of switching CNs.

\section{Introduction}

Coordination networks (CNs) ${ }^{1}$ are a class of covalent network solids comprised of metal or metal clusters (nodes) connected in two or more directions by organic (e.g. metal-organic frameworks, $\mathrm{MOFs}^{2,3}$ ), inorganic (e.g. Prussian blue and its

${ }^{a}$ Bernal Institute, Department of Chemical Sciences, University of Limerick, Limerick V94 T9PX, Republic of Ireland. E-mail: Michael.Zaworotko@ul.ie

${ }^{b}$ Department of Chemistry, Technical University of Munich, Lichtenbergstraße 4, 85748 Garching bei München, Germany 
analogues, $\mathrm{PBAs}^{4,5}$ ) or combinations of organic and inorganic (e.g. hybrid ultramicroporous materials, $\mathrm{HUMs}^{6}$ ) linker ligands (Fig. 1). CNs are a subset of coordination polymers $(\mathrm{CPs})^{7,8}$ and represent an extraordinarily diverse and growing class of metal-organic materials (MOMs). ${ }^{\mathbf{9}, 10}$ Interest in CNs is at least partly due to their inherent modularity and amenability to crystal engineering or reticular chemistry, ${ }^{11,12}$ which in turn facilitates the generation of closely related families of materials that allow for systematic structure-function studies. One property in particular has attracted the attention of researchers, namely porosity. Porosity is a direct outcome of the "node-and-linker" approach to the design of CNs that can be credited to Robson and Hoskins, who introduced the concept as a design principle for the generation of porous solids over 30 years ago. ${ }^{13,14}$ The existence of porosity deservedly attracts attention but is not in itself the only thing that makes CNs of special interest. Rather, it is the inherent modularity of CNs that brings with it an ability to design pore size, shape and chemistry. This in turn enables fine-tuning of properties to create potential utility for new energy-efficient technologies in areas of societal need, e.g. gas/vapour storage, separations, water purification, drug delivery and catalysis. ${ }^{15-19}$ Thus far, around 100000 CNs have been deposited in the MOF subset of the Cambridge Structural Database (CSD), ${ }^{20}$ thereby accounting for $c a .10 \%$ of entries in the CSD. ${ }^{21}$ The majority, perhaps $>99 \%$, of CNs thus far reported can be classified as "first generation" or "second generation" CPs, ${ }^{7,22-24}$ which either undergo structural collapse (first generation) or possess rigid structures like zeolites (second generation) upon guest removal, respectively. Herein, we address a small subset of "third generation" or "soft" CPs that are stimulus responsive in that they change structure when exposed to gases, vapours or liquids.

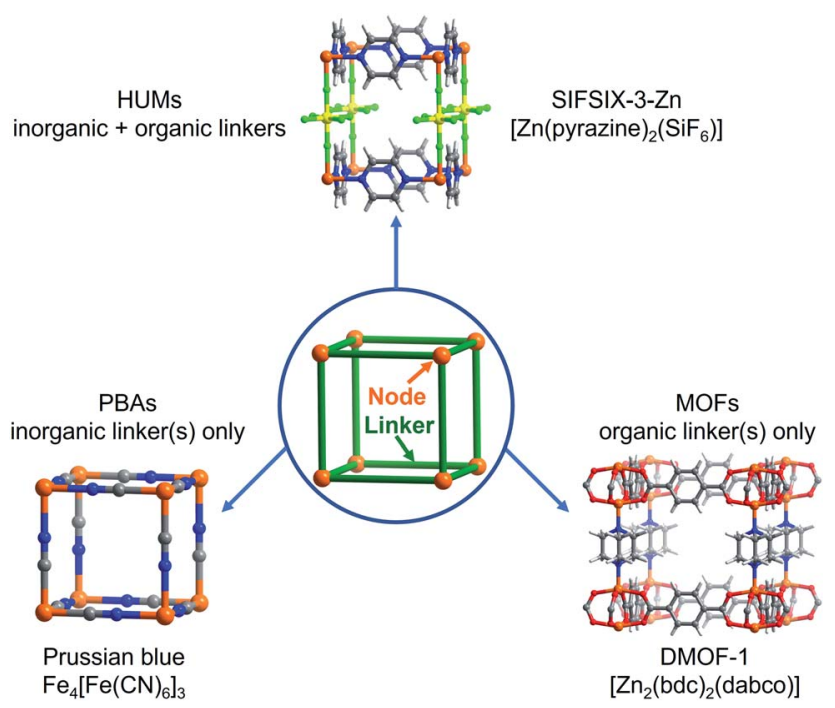

Fig. 1 CNs can be classified into three subsets by the type of linker ligands: inorganic only (e.g. PBAs); organic only (e.g. MOFs); hybrid (e.g. HUMs). The three subsets are exemplified by Prussian blue, DMOF-1 and SIFSIX-3-Zn, respectively. 
Seminal discoveries in the late 1990 s and early $2000 \mathrm{~s}^{25-29}$ introduced "third generation" $\mathrm{CPs}^{7,22-24}$ or "soft porous crystals". ${ }^{30,31}$ Third generation CNs exhibit structural flexibility when exposed to external stimuli such as light, ${ }^{32}$ heat, ${ }^{33}$ mechanical pressure ${ }^{34}$ and/or guest molecules. ${ }^{35-37}$ Pioneered by Kitagawa, Férey and others, ${ }^{7,22-24,38-41}$ flexible CNs have been comprehensively reviewed from different perspectives such as smart switches ${ }^{\mathbf{4 2 , 4 3}}$ multiscale design ${ }^{44}$ in situ characterisation, ${ }^{45}$ controlled flexibility design, ${ }^{46}$ simulation and computational studies ${ }^{47}$ and overall progress. ${ }^{4-50}$ Herein we focus upon a small but growing and potentially important subset of flexible CNs, namely those 2D (e.g. ELM-11 (ref. 28)) and $3 \mathrm{D}\left(\right.$ e.g. $\left.\left[\mathrm{Cu}_{2}(\mathrm{bdc})_{2}(\mathrm{bpy})\right]^{51}\right) \mathrm{CNs}$ that switch between closed (nonporous) and open (porous) phases.

A variety of terms have been coined to describe the flexibility of CNs including "accordionlike", ${ }^{26}$ "springlike", ${ }^{27,52}$ "spongelike", ${ }^{33,54}$ "breathing", 55 "swelling", ${ }^{56,57}$ "soft", ${ }^{30,31,58}$ "elastic", ${ }^{59,60}$ "dynamic", ${ }^{24,61,62}$ "stimuli-responsive", ${ }^{47,63,64}$ and "gateopening". ${ }^{28,65,66}$ An alternate approach to classify flexible CNs is to use their sorption isotherms and we have proposed a classification system based upon sorption isotherm types, namely type F-I to type F-V. ${ }^{67}$ IUPAC has classified type I isotherms as being characteristic of rigid microporous adsorbents thanks to the enhanced adsorbent-adsorbate interactions which results in micropore filling at very low relative pressure (Fig. 2a) ${ }^{68}$ In contrast, flexible microporous CNs usually exhibit distinct "stepped" or "S-shaped" isotherm profiles that are yet to be
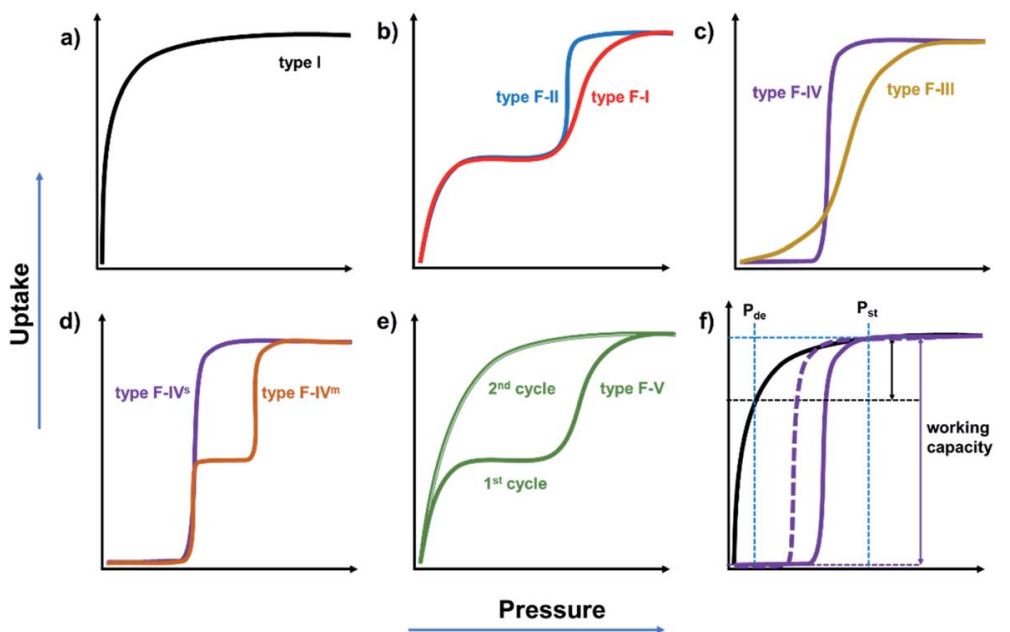

Fig. 2 Schematic illustration of sorption isotherm types exhibited by CNs. (a) Type I, typical of rigid microporous CNs; (b) type F-I (open to more open, gradual) and F-II (open to more open, sudden), associated with flexible microporous CNs; (c) type F-III (closed to open, gradual) and F-IV (closed to open, sudden) associated with switching nonporous CNs; (d) type F-IV isotherms can be sub-divided into single-step type F-IV's and multiplestep ( $\geq 2$ ) type $F-I V^{m}$ isotherms; (e) type $F-V$ isotherms are indicative of a shape memory effect in second and subsequent consecutive sorption cycles; ( $f$ ) comparison of working capacity between type I and F-IV isotherms with similar surface areas: black line = adsorption branch of type I isotherm (desorption branch overlays); solid/dash purple lines $=$ adsorption and desorption branches of type F-IV isotherm, respectively; $P_{\text {de: }}$ delivery pressure; $P_{\text {st }}$ : storage pressure. 
formally classified by IUPAC. When flexible CNs retain porosity after activation, a type I-like profile will be followed by the second step at a threshold pressure that coincides with a structural transformation from a less open phase to a more open phase. This transformation could be gradual (type F-I, e.g. the "breathing" effect in MIL-53(Cr) ${ }^{69}$ ) or sudden (type F-II, e.g. the "gate-opening" effect in ELM-12 (ref. 70)) (Fig. 2b). When flexible CNs are nonporous after activation, the transformation from a nonporous (closed) to a porous (open) phase can also occur gradually (type F-III, e.g. the "swelling" effect in $\left.\left[\mathrm{Co}_{2}(\mathrm{BME}-\mathrm{bdc})_{2}(\mathrm{dabco})\right]^{71}\right)$ or suddenly (type F-IV, e.g. the "switching" effect in $\left.\left[\mathrm{Zn}_{2}(\mathrm{BME}-\mathrm{bdc})_{2}(\mathrm{dabco})\right]^{71}\right)$ (Fig. 2c). In addition, type F-IV isotherms can be further sub-divided depending on the number of sorption steps, i.e., single-step type F-IV $\mathrm{V}^{\mathrm{s}}$ or multiple-step $(\geq 2)$ type F-IV ${ }^{\mathrm{m}}$ (Fig. 2d). ${ }^{72}$ We note that most of the flexible CNs reported to date undergo reversible structural changes in response to the presence/absence of external stimuli and that there are very few examples of flexible CNs that do not return to their activated forms after full desorption. There are, however, CNs that retain the structure of the fully open stage after the first sorption cycle and exhibit type I sorption isotherms during the subsequent cycles (type F-V, e.g. the "shape memory" effect in X-pcu-3-Zn-3i ${ }^{73}$ ) (Fig. 2e). Amongst the various isotherm types in Fig. 2, flexible CNs that exhibit type F-IV isotherms are perhaps the most desirable with respect to gas storage as they can offer higher working capacity than rigid porous materials with type I isotherms (Fig. 2f)..$^{72,74}$ It should be mentioned that hysteresis is a feature of most type F-IV isotherms and, to be of practical utility, the delivery pressure $\left(P_{\mathrm{de}}\right)$ must be lower than the desorption branch rather than the adsorption branch (Fig. 2f).

We adopt the term "switching" herein as it is consistent with the "on/off" nature of CNs that exhibit reversible "closed/open" structural changes of the type that affords type F-IV isotherms. Switching has also been used for other on/off events in materials chemistry such as thermal expansion/shrinkage, spin crossover, redox, photochromism, photoisomerization and valence tautomerism. ${ }^{42,43,75-77}$ In the following sections, we analyse and discuss reversible switching in the context of guest sorption by presenting case studies of switching CNs with particular emphasis upon structure-property relationships and the influence of variables such as metal node, linker ligand, and adsorbate.

\section{Switching CNs}

Whereas coordination complexes and organic molecules are long-known for the ability to exhibit guest inclusion or clathration that accompanies switching between closed and open phases, ${ }^{78-83}$ the first examples of 2D and 3D switching CNs were not reported until the beginning of the $21^{\text {st }}$ century (Fig. 3$){ }^{28,51}$ Werner complexes are prototypal coordination compounds and their guest-clathration ability was systematically studied by Schaeffer in $1957 .^{78}$ The associated sorption isotherms were reported in 1969 by Barrer's group, who studied the sorption behaviour of several Werner complexes upon exposure to a range of gases and vapours. ${ }^{79}$ Type F-IV isotherms were observed when the Werner complex $\left[\mathrm{Co}(\text { etpy })_{4}(\mathrm{NCS})_{2}\right]$ was exposed to benzene, toluene and xylenes and this phenomenon was attributed to closed/open phase transformations. We recently reported a related example of such a Werner complex and termed it as a Switching Adsorbent Molecular Material (SAMM). ${ }^{83}$ The first 2D switching CN, 


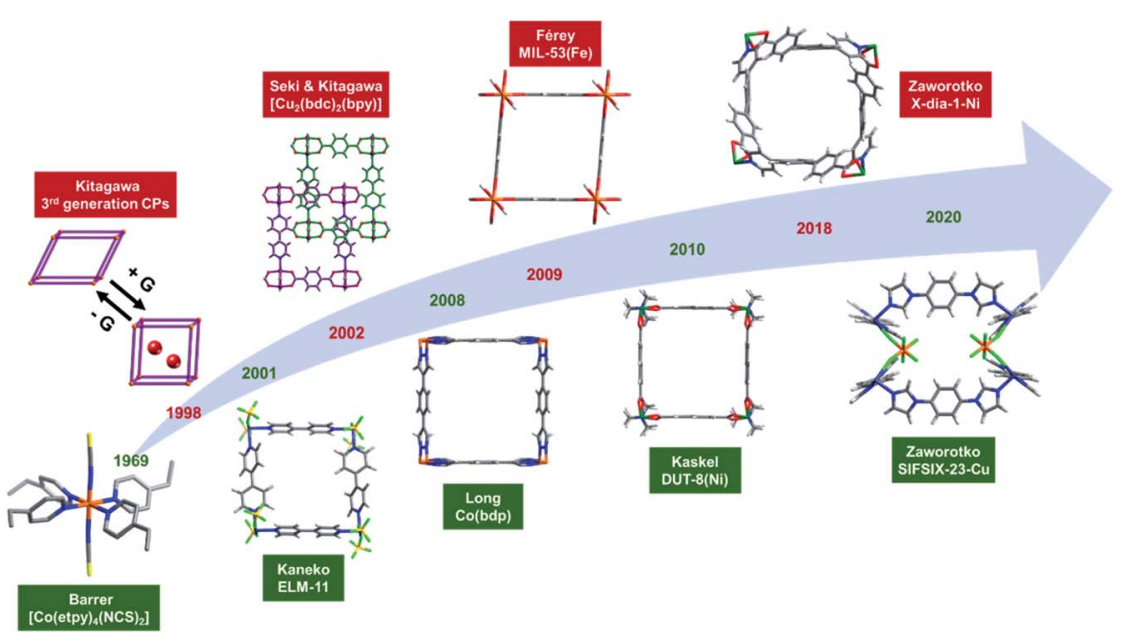

Fig. 3 Chronology of key developments related to switching CNs. 1969 (Barrer): type F-IV sorption isotherms observed in the Werner complex [Co(etpy) $\left.{ }_{4}(\mathrm{NCS})_{2}\right]_{;} 1998$ (Kitagawa): $3^{\text {rd }}$ generation CPs defined; 2001 (Kaneko): first 2D switching CN, ELM-11, reported; 2002 (Seki \& Kitagawa): first 3D switching and "shape-memory" CN, $\left[\mathrm{Cu}_{2}(\mathrm{bdc})_{2}(\mathrm{bpy})\right]$, detailed; 2008 (Long): type $\mathrm{F}-\mathrm{IV}^{\mathrm{m}}$ sorption isotherms observed in $\mathrm{Co}(\mathrm{bdp})$, currently the benchmark switching $\mathrm{CN}$ for $\mathrm{CH}_{4}$ storage; 2009 (Férey): reported the most widely studied switching CN: MIL-53(Fe); 2010 (Kaskel): benchmark $\mathrm{N}_{2}$ (77 K) and $\mathrm{CO}_{2}$ (195 K) uptakes for DUT-8(Ni); 2018 (Zaworotko): first dia topology switching CN, Xdia-1-Ni, and classification of the isotherm types for flexible CNs; 2020 (Zaworotko): first example of switching hybrid $\mathrm{CN}$ with inorganic and organic linkers, SIFSIX-23-Cu, published.

$\left[\mathrm{Cu}(\mathrm{bpy})_{2}\left(\mathrm{BF}_{4}\right)_{2}\right]$, ELM-11, ${ }^{28}$ was reported in 2001 and can be regarded as being comprised of linked Werner complexes which serve as molecular building blocks $\left(\mathrm{MBBs}^{84}\right)$. The first 3D switching CN, $\left[\mathrm{Cu}_{2}(\mathrm{bdc})_{2}(\mathrm{bpy})\right],{ }^{51}$ was reported in 2002 and features a 2D square lattice layer comprised of linked "paddle-wheel" MBBs that is pillared by bpy linkers to form a 2-fold interpenetrated 3D network. Altering the length of the vertical pillar and horizontal linker afforded a non-interpenetrated switching CN DUT-8(Ni) which set benchmark uptakes for $\mathrm{N}_{2}(77 \mathrm{~K})$ and $\mathrm{CO}_{2}(195$ $\mathrm{K}$ ) in switching CNs. ${ }^{113,114}$ Hybrid $\mathrm{CNs}^{6}$ with primitive cubic (pcu) topology can be generated from 2D square lattice (sql) CNs when an inorganic counter anion such as hexafluorosilicate can serve as a pillar ligand, as exemplified by the first switching hybrid CN, SIFSIX-23-Cu. ${ }^{151}$ Whereas the coordination spheres of Werner complexes, 2D sql CNs and 3D pcu CNs are chemically related, their dimensional rigidities can be different. ${ }^{40}$ In 2008, type $\mathrm{F}^{-\mathrm{IV}^{\mathrm{m}}}$ isotherms were observed in $\mathrm{Co}(\mathrm{bdp}),{ }^{101}$ which later set a benchmark for volumetric $\mathrm{CH}_{4}$ working capacity in the context of switching CNs. ${ }^{74}$ Although MIL-53 CNs were reported as early as 2002, a switching variant, MIL-53(Fe), was not introduced until 2009. ${ }^{106} \mathrm{X}-$ dia-1-Ni, reported in 2018, was the first example of a diamondoid (dia) topology switching $\mathrm{CN}$ and it was found to exhibit the second highest $\mathrm{CH}_{4}$ working capacity in switching CNs. ${ }^{67}$ Overall, around 60 switching CNs have now been reported (Table 1), with sql and pcu topology CNs being the most common 2D and 3D switching CNs, respectively. Whereas 2D switching CNs were reported first, the proportion of $3 \mathrm{D}$ switching $\mathrm{CNs}$ is currently much higher than 2D switching CNs 
Table 1 Tabulated chronology (2001-2020) of switching CNs

\begin{tabular}{|c|c|c|c|c|}
\hline CNs & Dimension & Guests & Year & Ref. \\
\hline ELM-11 & $2 \mathrm{D}$ & $\mathrm{N}_{2}, \mathrm{Ar}, \mathrm{O}_{2}, \mathrm{CH}_{4}, \mathrm{CO}_{2}, \mathrm{C}_{2} \mathrm{H}_{2}, \mathrm{C}_{4} \mathrm{H}_{10}$ & 2001 & $\begin{array}{l}28,72 \\
\text { and } \\
85-90\end{array}$ \\
\hline$\left[\mathrm{Co}(\mathrm{NCS})_{2}(3-\mathrm{pia})_{2}\right]$ & $2 \mathrm{D}$ & $\mathrm{Me}_{2} \mathrm{CO}$ & 2002 & 91 \\
\hline$\left[\mathrm{Cu}_{2}(\mathrm{pzdc})_{2}(\mathrm{dpyg})\right]$ & $3 \mathrm{D}$ & $\mathrm{MeOH}, \mathrm{H}_{2} \mathrm{O}$ & 2002 & 92 \\
\hline$\left[\mathrm{Cu}_{2}(\mathrm{bdc})_{2}(\mathrm{bpy})\right]$ & $3 \mathrm{D}$ & $\mathrm{N}_{2}, \mathrm{CH}_{4}, \mathrm{MeOH}, \mathrm{CO}_{2}$ & 2002 & 51 and 93 \\
\hline$\left[\mathrm{Cu}(\mathrm{dhbc})_{2}(\mathrm{bpy})\right]$ & $2 \mathrm{D}$ & $\mathrm{O}_{2}, \mathrm{~N}_{2}, \mathrm{CH}_{4}, \mathrm{CO}_{2}$ & 2003 & 65 and 94 \\
\hline$\left[\mathrm{Co}(\mathrm{NCS})_{2}(4-\text { peia })_{2}\right]$ & $2 \mathrm{D}$ & $\mathrm{Me}_{2} \mathrm{CO}$ & 2004 & 95 \\
\hline$[\mathrm{Cu}($ pyrdc $)(\mathrm{bpp})]$ & $2 \mathrm{D}$ & $\mathrm{CO}_{2}, \mathrm{MeOH}, \mathrm{EtOH}$ & 2005 & 96 \\
\hline MOF-508 & $3 \mathrm{D}$ & $\mathrm{N}_{2}, \mathrm{H}_{2}, \mathrm{CO}_{2}, \mathrm{C}_{2} \mathrm{H}_{2}$ & 2006 & $97-99$ \\
\hline$\left[\mathrm{Zn}(\mathrm{TCNQ})_{2}(\mathrm{bpy})\right]$ & $3 \mathrm{D}$ & $\mathrm{C}_{6} \mathrm{H}_{6}$ & 2007 & 100 \\
\hline$[\mathrm{Cd}(\mathrm{bpndc})(\mathrm{bpy})]$ & $2 \mathrm{D}$ & $\mathrm{O}_{2}, \mathrm{~N}_{2}, \mathrm{Ar}$ & 2008 & 66 \\
\hline Co(bdp)/Fe(bdp) & $3 \mathrm{D}$ & $\mathrm{N}_{2}, \mathrm{H}_{2}, \mathrm{CH}_{4}, \mathrm{CO}_{2}$ & 2008 & $\begin{array}{l}74 \text { and } \\
101-103\end{array}$ \\
\hline ELM-31 & $2 \mathrm{D}$ & $\mathrm{CO}_{2}$ & 2009 & 104 \\
\hline SNU-M11/SNU-M10 & $3 \mathrm{D}$ & $\mathrm{CO}_{2}$ & 2009 & 105 \\
\hline MIL-53(Fe) & $3 \mathrm{D}$ & $\mathrm{CH}_{4}, \mathrm{C}_{2} \mathrm{H}_{6}, \mathrm{C}_{3} \mathrm{H}_{8}, \mathrm{C}_{4} \mathrm{H}_{10}, \mathrm{CO}_{2}, \mathrm{C}_{8} \mathrm{H}_{10}$ & 2009 & $106-108$ \\
\hline$\left[\mathrm{Cd}_{2}(\mathrm{pzdc})_{2} \mathrm{~L}\right]$ & $3 \mathrm{D}$ & $\mathrm{CO}_{2}$ & 2009 & 109 \\
\hline$[\mathrm{Zn}(\mathrm{pydc})(\mathrm{dma})]$ & $3 \mathrm{D}$ & $\mathrm{N}_{2}, \mathrm{Ar}, \mathrm{CO}_{2}, \mathrm{H}_{2}, \mathrm{CH}_{4}$ & 2009 & 110 \\
\hline $\mathrm{Zn}(\mathrm{GA})_{2}$ & $3 \mathrm{D}$ & $\mathrm{CO}_{2}$ & 2010 & 111 \\
\hline CID-5 & $2 \mathrm{D}$ & $\mathrm{CO}_{2}$ & 2010 & 112 \\
\hline DUT-8(Ni) & $3 \mathrm{D}$ & $\begin{array}{l}\mathrm{CO}_{2}, \mathrm{~N}_{2}, \mathrm{Xe}, \mathrm{C}_{4} \mathrm{H}_{10}, \mathrm{C}_{2} \mathrm{H}_{4}, \mathrm{C}_{2} \mathrm{H}_{6}, \mathrm{MeCN} \\
\mathrm{C}_{7} \mathrm{H}_{8}, \mathrm{C}_{7} \mathrm{H}_{16}, \mathrm{CH}_{2} \mathrm{Cl}_{2}, \mathrm{CHCl}_{3}, \mathrm{CCl}_{4}\end{array}$ & 2010 & $113-117$ \\
\hline$\left[\mathrm{Zn}_{2}(\mathrm{bpdc})_{2}(\mathrm{bpee})\right]$ & $3 \mathrm{D}$ & $\begin{array}{l}\mathrm{N}_{2}, \mathrm{Ar}, \mathrm{CO}_{2}, \mathrm{C}_{2} \mathrm{H}_{2}, \mathrm{C}_{2} \mathrm{H}_{4}, \mathrm{C}_{2} \mathrm{H}_{6}, \mathrm{C}_{3} \mathrm{H}_{6}, \mathrm{C}_{3} \mathrm{H}_{8}, \\
\mathrm{C}_{4} \mathrm{H}_{10}\end{array}$ & 2010 & $\begin{array}{l}118 \text { and } \\
119\end{array}$ \\
\hline$\left[\mathrm{Zn}_{2}(\mathrm{bdc})_{2}(\mathrm{dfbpb})\right]$ & $3 \mathrm{D}$ & $\mathrm{O}_{2}, \mathrm{Ar}, \mathrm{CO}_{2}$ & 2011 & 120 \\
\hline $\begin{array}{l}{[\mathrm{Zn}(\mathrm{DIP}-} \\
\left.\mathrm{bdc})_{2}(\mathrm{dabco})\right] \\
{[\mathrm{Zn}(\mathrm{DB}-} \\
\left.\text { bdc })_{2}(\text { dabco })\right]\end{array}$ & $3 \mathrm{D}$ & $\mathrm{CO}_{2}$ & 2012 & 121 \\
\hline MIL-53(Sc) & $3 \mathrm{D}$ & $\mathrm{CO}_{2}$ & 2012 & $\begin{array}{l}122 \text { and } \\
123\end{array}$ \\
\hline [Ni(bdc)(bphy)] & $2 \mathrm{D}$ & $\mathrm{CO}_{2}$ & 2012 & 124 \\
\hline$\left[\mathrm{Cu}\left(\mathrm{CF}_{3} \mathrm{SO}_{3}\right)_{2}(\mathrm{bpp})_{2}\right]$ & $2 \mathrm{D}$ & $\mathrm{O}_{2}, \mathrm{CO}_{2}$ & 2013 & 125 \\
\hline$\left[\mathrm{Zn}_{2} \mathrm{~L}_{2}\right]$ & $3 \mathrm{D}$ & $\mathrm{N}_{2}, \mathrm{CH}_{4}$ & 2014 & 126 \\
\hline DynaMOF-100 & $3 \mathrm{D}$ & $\mathrm{C}_{8} \mathrm{H}_{10}, \mathrm{C}_{8} \mathrm{H}_{8}$ & 2014 & $\begin{array}{l}127 \text { and } \\
128\end{array}$ \\
\hline JLU-Liu3/JLU-Liu4 & $3 \mathrm{D}$ & $\mathrm{N}_{2}$ & 2014 & 129 \\
\hline$\left[\mathrm{Ag}_{2}(\mathrm{~L} 15)_{2}\right]$ & $3 \mathrm{D}$ & $\mathrm{CO}_{2}$ & 2014 & 130 \\
\hline$\left[\mathrm{Sm}(\mathrm{HL})(\mathrm{DMA})_{2}\right]$ & $3 \mathrm{D}$ & $\mathrm{CO}_{2}, \mathrm{CH}_{2} \mathrm{Cl}_{2}$ & 2015 & 131 \\
\hline f-MOF-1/f-MOF-2 & $3 \mathrm{D}$ & $\mathrm{CO}_{2}$ & 2016 & 132 \\
\hline $\begin{array}{l}\mathrm{Co}\left(\mathrm{F}_{2}-\mathrm{bdp}\right) / \mathrm{Co}\left(\mathrm{Me}_{2}-\right. \\
\mathrm{bdp})\end{array}$ & $3 \mathrm{D}$ & $\mathrm{N}_{2}, \mathrm{CH}_{4}$ & 2016 & 133 \\
\hline $\operatorname{Mn}(\text { ina })_{2}$ & $3 \mathrm{D}$ & $\mathrm{C}_{2} \mathrm{H}_{6}, \mathrm{C}_{3} \mathrm{H}_{6}, \mathrm{C}_{3} \mathrm{H}_{8}$ & 2016 & 134 \\
\hline JLU-Liu33 & $3 \mathrm{D}$ & $\mathrm{N}_{2}$ & 2017 & 135 \\
\hline$\left[\mathrm{Zn}_{2}(\mathrm{DPT})_{2}(\mathrm{bpy})\right]$ & $3 \mathrm{D}$ & $\mathrm{CO}_{2}$ & 2017 & 136 \\
\hline$\left[\mathrm{Zn}_{3}(\mathrm{bdc})_{2}(\mathrm{tz})_{2}\right]$ & $3 \mathrm{D}$ & $\mathrm{C}_{2} \mathrm{H}_{6}, \mathrm{C}_{3} \mathrm{H}_{8}, \mathrm{C}_{4} \mathrm{H}_{10}$ & 2017 & 137 \\
\hline$[\mathrm{Co}(\mathrm{VTTF})]$ & $2 \mathrm{D}$ & $\mathrm{C}_{2} \mathrm{H}_{4}$ & 2017 & 138 \\
\hline DUT-98 & $3 \mathrm{D}$ & $\mathrm{N}_{2}, \mathrm{H}_{2} \mathrm{O}$ & 2017 & $\begin{array}{l}139 \text { and } \\
140\end{array}$ \\
\hline CPM-325 & $3 \mathrm{D}$ & $\mathrm{N}_{2}, \mathrm{CO}_{2}$ & 2018 & 141 \\
\hline $\mathrm{Cd}(\mathrm{miba})_{2}$ & $3 \mathrm{D}$ & $\mathrm{CO}_{2}$ & 2018 & 142 \\
\hline$\left[\mathrm{Zn}_{2}(\mathrm{tdc})_{2}(\mathrm{pvq})\right]$ & $3 \mathrm{D}$ & $\mathrm{N}_{2}$ & 2018 & 143 \\
\hline
\end{tabular}


Table 1 (Contd.)

\begin{tabular}{|c|c|c|c|c|}
\hline CNs & Din & Guests & Year & Ref. \\
\hline $\begin{array}{l}\mathrm{Zn}_{2}(\mathrm{BME}- \\
\mathrm{bdc})_{2}(\text { dabco })\end{array}$ & $3 \mathrm{D}$ & $\mathrm{CO}_{2}$ & 2018 & 71 \\
\hline X-dia-1-Ni & $3 \mathrm{D}$ & $\mathrm{CO}_{2}, \mathrm{CH}_{4}$ & 2018 & 67 \\
\hline sql-1-Co-NCS & $2 \mathrm{D}$ & $\mathrm{CO}_{2}, \mathrm{C}_{8} \mathrm{H}_{10}$ & 2018 & $\begin{array}{l}144 \text { and } \\
145\end{array}$ \\
\hline $\begin{array}{l}\text { X-pcu- } n \text {-Zn, } n=5,6 \text {, } \\
7,8\end{array}$ & $3 \mathrm{D}$ & $\mathrm{CO}_{2}, \mathrm{C}_{2} \mathrm{H}_{2}$ & 2018 & $\begin{array}{l}146 \text { and } \\
147\end{array}$ \\
\hline NJU-Bai8 & $3 \mathrm{D}$ & $\mathrm{C}_{3} \mathrm{H}_{6}, \mathrm{C}_{3} \mathrm{H}_{8}$ & 2018 & 148 \\
\hline$\left[\mathrm{Zn}_{2}(\mathrm{ndc})_{2}(\mathrm{bpa})\right]$ & $3 \mathrm{D}$ & $\mathrm{CO}_{2}$ & 2019 & 149 \\
\hline$[\mathrm{Cu}($ HIsa-az-dmpz)] & $3 \mathrm{D}$ & $\mathrm{N}_{2}, \mathrm{CO}_{2}$ & 2019 & 150 \\
\hline $\begin{array}{l}\text { SIFSIX-23-Cu (NTU- } \\
65)\end{array}$ & $3 \mathrm{D}$ & $\mathrm{N}_{2}, \mathrm{CO}_{2}, \mathrm{C}_{2} \mathrm{H}_{2}, \mathrm{C}_{2} \mathrm{H}_{4}$ & 2020 & $\begin{array}{l}151 \text { and } \\
152\end{array}$ \\
\hline ELM-13 & $2 \mathrm{D}$ & $\mathrm{N}_{2}, \mathrm{O}_{2}, \mathrm{Ar}, \mathrm{NO}, \mathrm{CO}_{2}$ & 2020 & 153 \\
\hline JUK-8 & $3 \mathrm{D}$ & $\mathrm{CO}_{2}, \mathrm{H}_{2} \mathrm{O}$ & 2020 & 154 \\
\hline
\end{tabular}

$(\sim 4: 1)$. This is likely a reflection of the larger number of 3D CNs (especially MOFs) that have been studied for their sorption properties in the past two decades but should not imply any prejudice in favour of modularity or properties for 3D CNs versus 2D CNs.

Switching between a closed and a single open phase generally results in singlestep type $\mathrm{F}^{-I V} \mathrm{~V}^{\mathrm{S}}$ isotherms ${ }^{51,65,66,71,74}$ whereas switching between closed and multiple open phases usually affords multiple-step type F-IV ${ }^{\mathrm{m}}$ isotherms (Fig. 2d and 4). ${ }^{72,85-87}$ The number of structural transitions and/or sorption steps in a switching $\mathrm{CN}$ can be influenced by factors such as temperature, pressure and adsorbate as exemplified by ELM-11..$^{72,85-87}$ Several of the prototypal switching CNs are modular and amenable to crystal engineering through systematic variation of metal moieties, linker ligands, sorbates or a combination thereof. Importantly, in many published reports, both the closed and open phases are structurally characterized and/or computationally modelled, thereby providing insight into both the mechanism of switching and the nature of the sorbent-sorbate interactions

a)

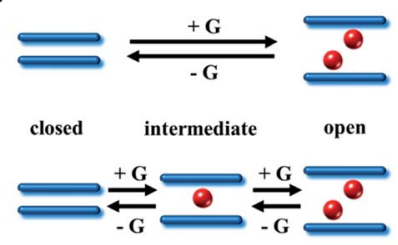

b)

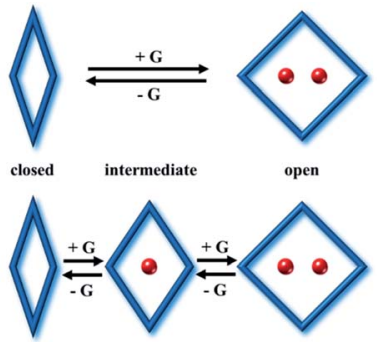

Fig. 4 Schematic illustration of the types of structural transformations in (a) 2D and (b) 3D switching CNs induced by sorbate/guest molecules (G, red balls). Transformation between closed and open phases typically results in a single-step type F-IV ${ }^{s}$ isotherm (top). Transformation between closed, intermediate (partially open) and fully open phases generally leads to a type $\mathrm{F}-\mathrm{IV}^{\mathrm{m}}$ isotherm (bottom). 
that drive the switching event. In the following sections, we present case studies of representative switching CNs and succinctly analyse their switching behaviour.

\subsection{Examples of 3D switching CNs}

2.1.1 MIL-53(M) family [M(OH)(bdc)]. The MIL-53 family of CNs represents perhaps the most widely studied family of flexible CNs thanks to the contributions of Férey and others. ${ }^{155}$ The metals (M) of MIL-53 are trivalent, e.g. Cr, Al, Fe, Sc, Ga or In. ${ }^{156-161}$ The structure of MIL-53(M) CNs is sustained by infinite trans corner sharing $\left[\mathrm{MO}_{4}(\mathrm{OH})_{2}\right]$ octahedra that form $1 \mathrm{D}$ chains by serving as rod building blocks, RBBs, ${ }^{162-164}$ which are cross-linked through bdc ligands (bdc $=$ 1,4-benzenedicarboxylate) to afford sra topology networks (Fig. 5). ${ }^{162}$ The resulting 1D rhombic tunnels are occupied by solvent or guest molecules. The first members of the MIL-53(M) family, MIL-53(Cr) and MIL-53(Al), were reported in 2002 and 2003, respectively. ${ }^{156,157}$ Initial studies focused on structural transformations during hydration-dehydration processes. ${ }^{\mathbf{1 6 5 , 1 6 6}}$ Large and reversible phase transformation between the activated "open" phase (MIL-53ht, ht $=$ high temperature) and hydrated "contracted" phase (MIL-53lt, lt = low temperature) was revealed and this "breathing" phenomenon remains a rarity even after two decades. A superhydrated "open" phase was obtained by immersing MIL-53(Cr) in water and was reported in $2011 .^{\mathbf{1 6 7}}$

Gas sorption studies involving $\mathrm{N}_{2}, \mathrm{H}_{2}, \mathrm{CH}_{4}$ and $\mathrm{CO}_{2}$ on MIL-53(Cr, $\left.\mathrm{Al}\right)$ revealed guest-dependent sorption profiles. ${ }^{69,156,157}$ For $\mathrm{N}_{2}, \mathrm{H}_{2}$ and $\mathrm{CH}_{4}$, the sorption isotherms are type I as expected for rigid microporous CNs and zeolites (Fig. 2a). In contrast, for $\mathrm{CO}_{2} \mathrm{MIL}-53(\mathrm{Cr}, \mathrm{Al})$ were observed to exhibit type F-I sorption isotherms (Fig. 6a). ${ }^{69}$ This was attributed to $\mathrm{CO}_{2}$ molecules interacting strongly with the hydroxide moieties that line the rhombic tunnels, resulting in pore contraction at low pressure and pore opening at high pressure. ${ }^{168} \mathrm{~A}$ two-step type F-I isotherm was observed with polar vapours (e.g. $\mathrm{MeOH}, \mathrm{EtOH})$ and $\mathrm{C}_{2}-\mathrm{C}_{8}$ hydrocarbon sorbates. ${ }^{169-171}$

Substitution of the metal nodes by $\mathrm{Fe}(\mathrm{III})$ or Sc(III) resulted in nonporous "closed" phases in MIL-53(Fe or Sc) after activation. ${ }^{\mathbf{1 2 2 , 1 2 3 , 1 7 2}}$ Compared to MIL53(Sc), MIL-53(Fe) has been more widely subjected to study. $\mathrm{CO}_{2}$ sorption on MIL-53(Fe) revealed a multi-step type F-IV ${ }^{\mathrm{m}}$ isotherm (Fig. 6b). ${ }^{107}$ Other gases such as light hydrocarbons were observed to exhibit the same trend but with
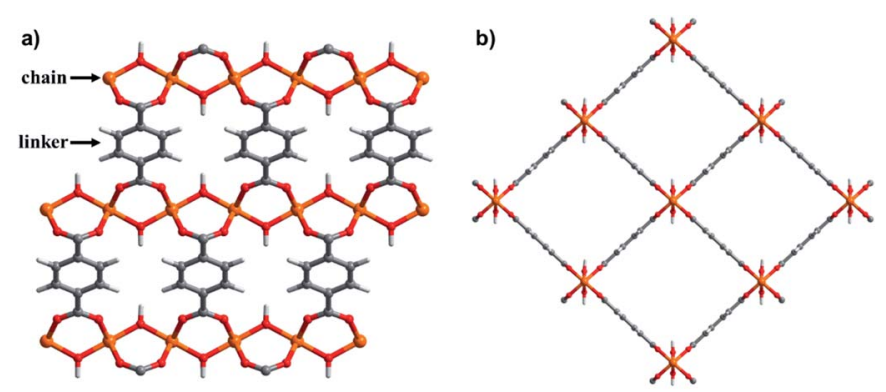

Fig. 5 Crystal structures of MIL-53(M): (a) $\mathrm{MO}_{4}(\mathrm{OH})_{2}$ chains connected by bdc linkers; (b) 1D rhombic channels in the open phase, guest molecules are omitted for clarity. Orange: $\mathrm{M}(\mathrm{Cr}, \mathrm{Al}, \mathrm{Fe}$, etc.), red: $\mathrm{O}$, grey: $\mathrm{C}$, light grey: $\mathrm{H}$. 

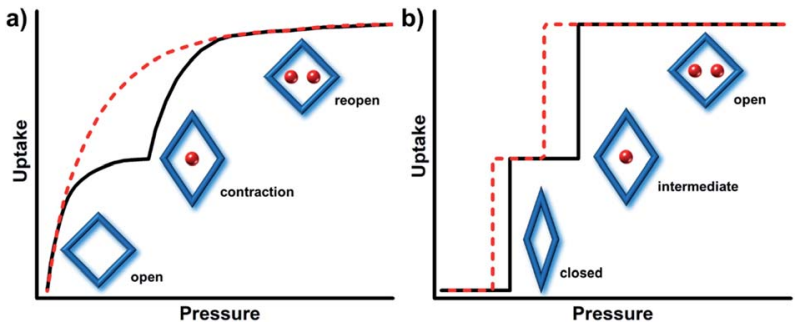

Fig. 6 Schematic illustrations of the sorption isotherm types reported for the MIL-53(M) family. (a) Type F-I isotherms with open to less open to open transformations as observed in MIL-53(Cr, Al); (b) type F-IVm isotherm with closed to open to more open transformations as seen for MIL-53(Fe, Sc). Black solid line: adsorption curve; red dash line: desorption curve.

adsorbate-dependent switching pressures and uptakes (Fig. 7a). ${ }^{106}$ The structural transformations of MIL-53(Fe) involve at least two intermediate phases (ip1 and ip2) in between its closed (cp) and open (op) phases (Fig. 7b). A variety of liquid organics, including protic/nonprotic and polar/nonpolar molecules, resulted in various degrees of expansion in MIL-53(Fe). ${ }^{173}$ Increases in volume per formula unit $\left(V_{\text {f.u. }}\right)$ between the closed and various open phases varied from 2 to $77 \%$ (Table 2 ).

Ligand functionalization impacts the flexibility of MIL-53(Fe) with various adsorbates (Table 3) as exemplified by MIL-53(Fe)-X variants prepared from a library of functionalised bdc ligands (Fig. 8a). ${ }^{179-183}$ Except for MIL-53(Fe)-2OH, the activated "dry" phases of MIL-53(Fe)-X exhibited larger volumes than MIL53(Fe), consistent with the ip1 or ip2 phase of MIL-53(Fe) (Fig. 8b, black line). ${ }^{181} 77 \mathrm{~K} \mathrm{~N}_{2}$ sorption studies revealed no porosity (closed phases) except for MIL-53(Fe)-2 $\mathrm{CF}_{3}$. The larger pore volumes of activated MIL-53(Fe)-X phases were attributed to steric hindrance between functional groups which prevent pore closure. Hydration was found to result in only negligible changes to the unit-cell volumes (Fig. 8b, red line). MIL-53(Fe)-2OH is an exception as it was found to exhibit high water uptake thanks to hydrogen bonding between hydroquinolic $\mathrm{OH}$ groups and water molecules. Regarding other solvents, MIL-53(Fe)-2COOH was observed to be an outlier. It remained in its closed phase regardless of the liquid used and exhibited no significant solvent uptake. This outcome was
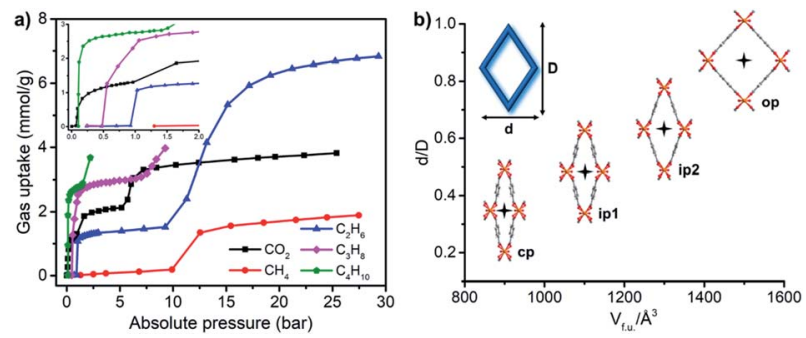

Fig. 7 (a) Gas sorption isotherms recorded for MIL-53(Fe) at 303 K; (b) different phases observed in MIL-53(Fe), $\mathrm{cp}=$ closed phase, ip = intermediate phase, $\mathrm{op}=$ open phase. 
Table 2 Guest sorption studies on MIL-53(Fe) and the corresponding volumes per formula unit of guest-loaded phases ${ }^{a}$

\begin{tabular}{|c|c|c|c|}
\hline Guests & $V_{\text {f.u. }}\left(\AA^{3}\right)$ & Year & Ref. \\
\hline py & 1393 & 2005 & 158 \\
\hline Closed phase $/ \mathrm{H}_{2} \mathrm{O}$ & $900 / 987$ & 2008 & 172 \\
\hline IPA/DMSO/py/DMF/quinone/THF & $1271 / 1304 / 1395 / 1398 / 1455 / 1471$ & 2008 & 173 \\
\hline $\mathrm{CHCl}_{3} / \mathrm{DEF} / \mathrm{EA} / \mathrm{NB} /$ toluene/EtOH & $1534 / 1534 / 1566 / 1581 / 1582 / 1585$ & & \\
\hline DMC/MeOH/BuOH/lutidine/MeCN/MX & $1588 / 1591 / 1592 / 1593 / 1594 / 1587$ & & \\
\hline Ibuprofen & 1407 & 2008 & 174 \\
\hline $\mathrm{CH}_{4}$ & 964 & 2009 & 106 \\
\hline $\mathrm{C}_{2} \mathrm{H}_{6}$ (three phases) & $984 / 1186 / 1587$ & & \\
\hline $\mathrm{C}_{3} \mathrm{H}_{8}$ (three phases) & $1001 / 1272 / 1565$ & & \\
\hline $\mathrm{C}_{4} \mathrm{H}_{10}$ (three phases) & $1014 / 1311 / 1566$ & & \\
\hline Lutidine/py/ $\mathrm{H}_{2} \mathrm{O}$ & $1213 / 1398 / 1000$ & 2010 & 175 \\
\hline MeOH (two phases) & $1192 / 1595$ & 2011 & 176 \\
\hline EtOH (two phases) & $1199 / 1580$ & & \\
\hline 1-PrOH (two phases) & $1243 / 1511$ & & \\
\hline 2-PrOH & 1271 & & \\
\hline $\mathrm{OX} / \mathrm{MX} / \mathrm{PX}$ & $1579 / 1584 / 1582$ & 2012 & 177 \\
\hline bzta/bztp & $1590 / 1591$ & 2013 & 178 \\
\hline $\mathrm{CO}_{2}$ (three phases) & $917 / 1083 / 1563$ & 2015 & 107 \\
\hline
\end{tabular}

attributed to strong intraframework hydrogen bonding interactions that drive the pores to remain closed. In general, pore opening in functionalised MIL-53(Fe)-X variants is governed by a balance between the intrinsic stability of the closed and open phases and guest-framework interactions. The influence of the linker on the switching of MIL-53(Fe) upon $\mathrm{CO}_{2}$ and $\mathrm{C}_{1}-\mathrm{C}_{9}$ hydrocarbon adsorption was also systematically studied (Fig. 8c). ${ }^{182,183}$ With the exception of methane, closed to open transformations occurred through an intermediate phase $\left(\mathrm{X}=\mathrm{Cl}, \mathrm{Br}, \mathrm{CH}_{3}\right)$, thus differing from the parent, MIL-53(Fe), for which two intermediate phases were observed (Fig. 8b). MIL-53(Fe)-2COOH and MIL-53(Fe)- $\mathrm{NH}_{2}$ remained closed when exposed to $\mathrm{CO}_{2}$ or hydrocarbons. ${ }^{182,183} \mathrm{~A}$ combination of steric effects and intraframework interactions in MIL-53(Fe)-X was deemed responsible for these observations.

Table 3 Chronology of MIL-53(Fe)-X variants

\begin{tabular}{llr}
\hline MIL-53(Fe)-X & Guests & Year Ref. \\
\hline $2 \mathrm{COOH}$ & $\mathrm{H}_{2} \mathrm{O}$ & 2004179 \\
$\mathrm{NH}_{2}$ & $\mathrm{H}_{2} \mathrm{BDC}-\mathrm{NH}_{2}$ & 2008180 \\
$\mathrm{Cl}, \mathrm{Br}, \mathrm{NH}_{2}, \mathrm{CH}_{3}, 2 \mathrm{OH}, 2 \mathrm{CF}_{3}$, & $\mathrm{H}_{2} \mathrm{O}$, pyridine, EtOH, tetrachloroethane & 2010181 \\
$2 \mathrm{COOH}$ & & \\
$\mathrm{Cl}, \mathrm{Br}, \mathrm{NH}_{2}, \mathrm{CH}_{3}$ & $\mathrm{CH}_{4}, \mathrm{C}_{2} \mathrm{H}_{6}, \mathrm{C}_{3} \mathrm{H}_{8}, \mathrm{C}_{4} \mathrm{H}_{10}, \mathrm{C}_{6} \mathrm{H}_{14}, \mathrm{C}_{7} \mathrm{H}_{16}, \mathrm{C}_{8} \mathrm{H}_{18}, 2011182$ \\
& $\mathrm{C}_{9} \mathrm{H}_{20}$ & \\
$\mathrm{Cl}, \mathrm{Br}, \mathrm{NH}_{2}, \mathrm{CH}_{3}, 2 \mathrm{COOH}$ & $\mathrm{CO}_{2}$ & 2012183
\end{tabular}


a)<smiles>Cc1cc(C(=O)O)ccc1C(=O)O</smiles><smiles>O=C(O)Oc1cc(C(=O)O)ccc1O</smiles><smiles>Cc1ccc(O)c(OCCO)c1</smiles><smiles>Cc1cc(C(=O)O)ccc1C(=O)O</smiles><smiles>O=C(O)c1cc(O)c(O)cc1O</smiles><smiles>Cc1cc(C(=O)O)cc(C)c1C(=O)O</smiles><smiles>O=C(O)c1cc(O)c(C(=O)O)cc1O</smiles>

c)

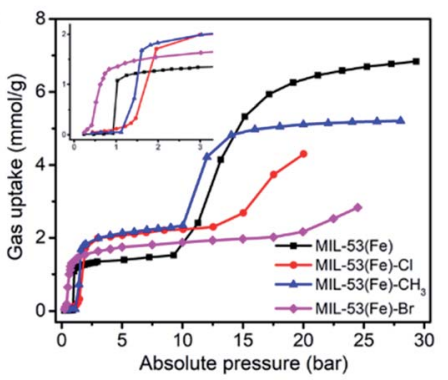

b)

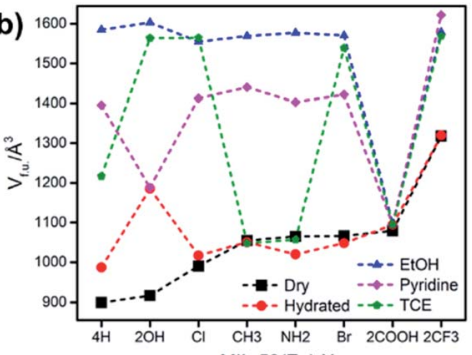

d)

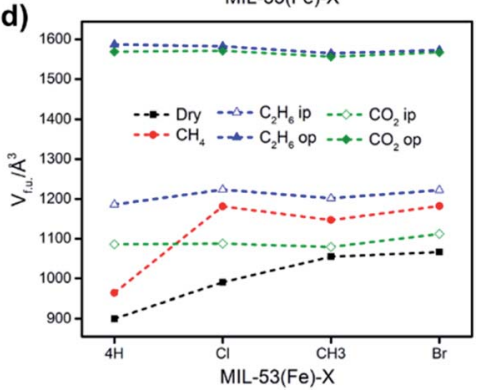

Fig. 8 (a) The functionalised bdc ligands used to synthesise MIL-53(Fe)-X variants; (b) and (d) volume per formula unit $\left(V_{\text {f.u. }}\right)$ of MIL-53(Fe)-X variants under different conditions, $4 \mathrm{H}=$ MIL-53(Fe); (c) $\mathrm{C}_{2} \mathrm{H}_{6}$ sorption isotherms of MIL-53(Fe)-X at $303 \mathrm{~K}$.

2.1.2 Pillared-layer CNs. Pillared-layer coordination networks (PLCNs) are a diverse class of CNs that have been extensively studied in the past two decades. ${ }^{6,184-188}$ Most PLCNs feature pcu or "jungle-gym" geometry and the most commonly studied subset has the general formula $\left[\mathrm{M}_{2} \mathrm{~L}_{2} \mathrm{P}\right]_{n}(\mathrm{M}=$ divalent metal cation; class I: $\mathrm{L}=$ dicarboxylate linker and $\mathrm{P}=\mathrm{N}$-donor pillar; class $\mathrm{II}: \mathrm{L}=\mathrm{N}-$ donor linker and $\mathrm{P}=$ inorganic anionic pillar). ${ }^{188}$ Class I PLCNs comprise twodimensional sql topology networks linked by dicarboxylate linker ligands (L) which are pillared in the third dimension by neutral N-donor linker ligands (P) to form pcu topology frameworks (Fig. 9). The metal nodes of the prototypal PLCNs are dinuclear paddle-wheel $\left[\mathrm{M}_{2}(\mathrm{COO})_{4}\right]$ that serve as 6-connected (6c) MBBs.

The prototypal PLCN, $\left[\mathrm{Zn}_{2}(\mathrm{bdc})_{2}(\text { dabco })\right]_{n}$ (dabco $=$ 1,4-diazabicyclo[2.2.2] octane), is widely known as DMOF-1. The bdc-linked sql nets are comprised of
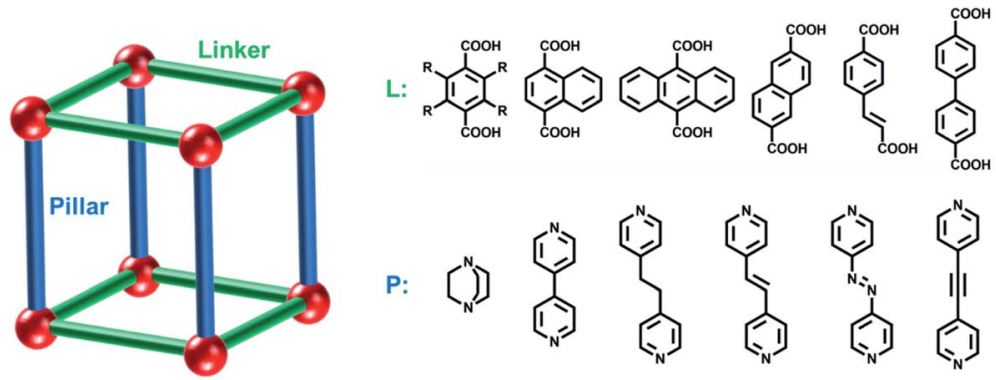

\section{P:}<smiles>c1cc(-c2ccncc2)ccn1</smiles><smiles>c1cc(Cc2cc[nH]c2)ccn1</smiles><smiles>c1cc(Cc2cc[nH]c2)ccn1</smiles><smiles></smiles><smiles>C(=C1C=CN=C1)=C1C=CN=C1</smiles>

Fig. 9 Schematic illustration of pillared-layer coordination networks with examples of linker (L) and pillar ligands (P). 
$\left[\mathrm{Zn}_{2}(\mathrm{COO})_{4}\right]$ paddle-wheel moieties that are pillared by dabco ligands to form the resulting pcu framework. ${ }^{189-192}$ Sorption studies using $\mathrm{N}_{2}$ and $\mathrm{H}_{2}$ on DMOF-1 revealed type I isotherms, an indication of structural rigidity. ${ }^{189}$ However, benzene was found to induce structural deformation of DMOF-1 from square to rhombic grids. Interestingly, sorption of IPA, MeOH and EtOH on DMOF-1 afforded two-step type F-I isotherms. ${ }^{190,191}$ The first step resulted from contraction whereas the second step corresponded to pore reopening. Molecular simulations have provided insight into these structural changes. ${ }^{\mathbf{1 9 2}}$

The ready availability/accessibility of numerous dicarboxylic acids and dipyridyl ligands has enabled facile linker and pillar functionalization/substitution of DMOF-1 to create families of related pcu structures. In addition, Zn(II) can be replaced by several other transition metals. Studies on the sorption properties of DMOF-1 derivatives have revealed profound effects upon sorption profiles..$^{51,71,93,97-99,113-121,146,147}$ For example, the DMOF-1 analogue $\left[\mathrm{Ni}_{2}(\mathrm{ndc})_{2}(-\right.$ dabco) $]_{n}$ (ndc $=1,4$-naphthalenedicarboxylate), DUT-8(Ni), was reported to exhibit large and reversible expansion/shrinkage between its closed and open phases. ${ }^{\mathbf{1 1 3 - 1 1 7}}$ Introduced by Kaskel's group in 2010, DUT-8(Ni) is isostructural to DMOF-1, the main difference being the length of linker ligands. The longer ndc linker in DUT-8(Ni) not only leads to larger pores and higher sorption uptakes, but results in single-step type $\mathrm{F}-\mathrm{IV}^{\mathrm{S}}$ isotherms induced by $\mathrm{N}_{2}, \mathrm{Xe}, \mathrm{CO}_{2}$ and $n$-butane. ${ }^{113}$ As-synthesised DUT-8(Ni) transforms to its closed phase during desolvation accompanied by a colour change from green to yellow. Compared to its open phase, the paddle-wheel units in the closed phase are strongly distorted (Fig. 10a and $\mathrm{b}$ ) and the $\mathrm{N}-\mathrm{Ni}-\mathrm{Ni}-\mathrm{N}$ atoms of paddle-wheel units and dabco molecules are arranged in zigzag rather than linear fashion (Fig. 10c and d) ${ }^{115}$ Induced by guest sorption, the structural transformation from closed $\left(V_{\text {f.u. }}=648 \AA^{3}\right)$ to open $\left(V_{\text {f.u. }}=1644 \AA^{3}\right)$ phases involves $>150 \%$ volume expansion without covalent bond breakage (Fig. 10e and f), one of the largest volume changes reported for flexible CNs. This large expansion enables exceptionally high $\mathrm{N}_{2}\left(\sim 700 \mathrm{~cm}^{3} \mathrm{~g}^{-1}\right)$ and $\mathrm{CO}_{2}$ $\left(\sim 600 \mathrm{~cm}^{3} \mathrm{~g}^{-1}\right)$ uptakes (Fig. $\left.10 \mathrm{~g}\right)$.

Kaskel's group subsequently reported that other metals can sustain DUT-8(M) analogues $(\mathrm{M}=\mathrm{Co}, \mathrm{Zn}, \mathrm{Cu})$ and exhibit distinct sorption profiles. ${ }^{114}$ Depending on the metal ion used, DUT-8 variants were found to exhibit reversible (DUT-8(Ni), DUT-8(Co)), irreversible (DUT-8(Zn)) or no (DUT-8(Cu)) transformation upon

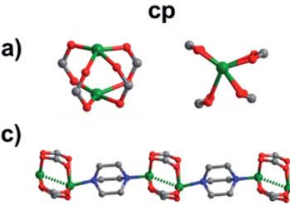

e)

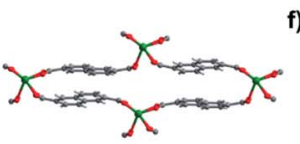

b)

d)
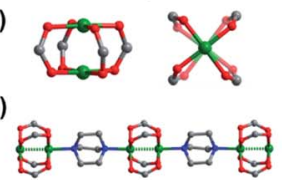

f)

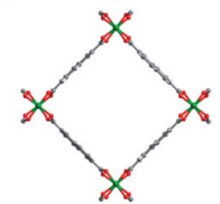

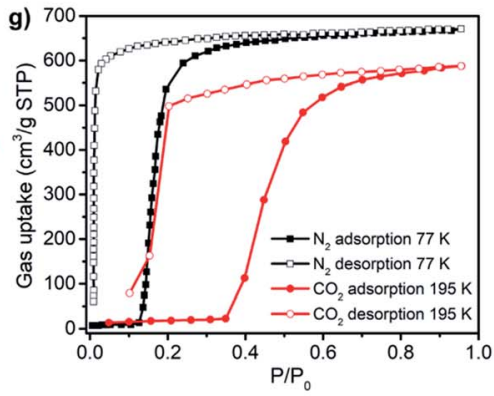

Fig. 10 Comparison of the closed (a, c, e) and open (b, d, f) phases of DUT-8(Ni); (g) $\mathrm{N}_{2}$ (77 $\mathrm{K})$ and $\mathrm{CO}_{2}(195 \mathrm{~K})$ sorption isotherms of DUT-8(Ni). 
activation and/or guest sorption. It was noted that the particle size of DUT-8(Ni) can influence sorption profiles, which were either type $\mathrm{F}^{-\mathrm{IV}^{\mathrm{S}}}$ (particle size $>1$ $\mu \mathrm{m}$ ) or type I (particle size $<500 \mathrm{~nm}$ ). ${ }^{\mathbf{1 1 6 , 1 9 3 , 1 9 4}}$ A similar "downsizing" effect was also reported for the DMOF-1 analogue $\left[\mathrm{Cu}_{2}(\mathrm{bdc})_{2}(\mathrm{bpy})\right] \cdot{ }^{93}$

Recently, our group reported the structures and sorption properties of a series of DMOF-1 variants, namely $\left[\mathrm{Zn}_{2}(\mathrm{DMTDC})_{2}(\mathrm{P})\right]$, X-pcu- $n$ - $\mathrm{Zn}(n=5, \mathrm{P}=1$,2-di (4-pyridyl)-ethylene (dpe); $n=6, \mathrm{P}=1$,2-bis(4-pyridyl)ethane (bpe); $n=7$, $\mathrm{P}=$ 1,2-bis(4-pyridyl)acetylene (bpa); $n=8, \mathrm{P}=4,4^{\prime}$-azopyridine (apy); $\mathrm{H}_{2}$ DMTDC $=3$,4-dimethylthieno[2,3- $b$ thiophene-2,5-dicarboxylic acid). ${ }^{\mathbf{1 4 6 , 1 4 7}}$ The four pillar ligands used are longer than dabco and enable 2-fold interpenetration in the X-pcu- $n$-Zn family (Fig. 11a). The as-synthesised "open” phases, X-pcu- $n$-Zn$\alpha$, were obtained by solvothermal synthesis with solvent molecules occupying voids and calculated guest-accessible volumes of $c a$. 45\% (Fig. 11b). Single-crystal X-ray diffraction (SCXRD) studies revealed that activation of X-pcu- $n-Z n-\alpha$ resulted in "closed" nonporous phases, X-pcu- $n-\mathrm{Zn}-\beta$, with unit cell volumes reduced by $c a$. $35 \%$ (Fig. 11c). $\mathrm{CO}_{2}, \mathrm{C}_{2} \mathrm{H}_{2}$ and $\mathrm{C}_{2} \mathrm{H}_{4}$ sorption on $\mathrm{X}$-pcu- $n$ - $\mathrm{Zn}-\beta$ revealed switching behaviour with comparable uptakes but different switching pressures (Fig. 11d-f). Up to $250 \mathrm{~cm}^{3} \mathrm{~g}^{-1} \mathrm{CO}_{2}$ uptake and good recyclability ( $>35$ sorption cycles) make Xpcu- $n$-Zn only the second family of flexible CNs to exhibit both high uptake and reversibility. The switching pressures for the three gases studied followed a consistent trend: X-pcu-6-Zn- $\beta<$ X-pcu-5-Zn- $\beta<$ X-pcu-7-Zn- $\beta<$ X-pcu-8-Zn$\beta$ which was attributed to the relative degree of conformational flexibility of the pillar ligands. ${ }^{\mathbf{1 4 7}}$

By exploring longer linkers and extended pillar ligands, other interpenetrated derivatives of DMOF-1 have been obtained. For example, with $4,4^{\prime}$-biphenyldicarboxylate as the linker and 1,4-bis(4-pyridyl)benzene or 4,4'-bis(4-pyridyl) biphenyl as the pillar, 3-fold interpenetrated CNs X-pcu-3-Zn and X-pcu-1-Zn were synthesised, respectively. ${ }^{73,195}$ Although interpenetration inevitably reduces guest-accessible voids, X-pcu-3-Zn and X-pcu-1-Zn nevertheless exhibited ca. 45\%

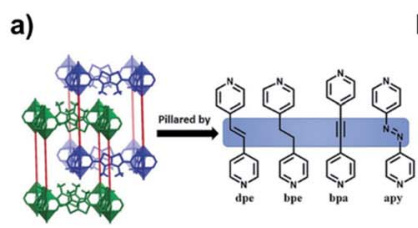

b)

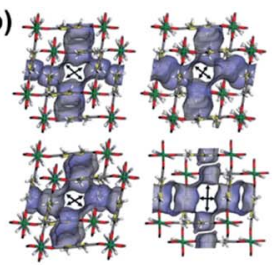

c)
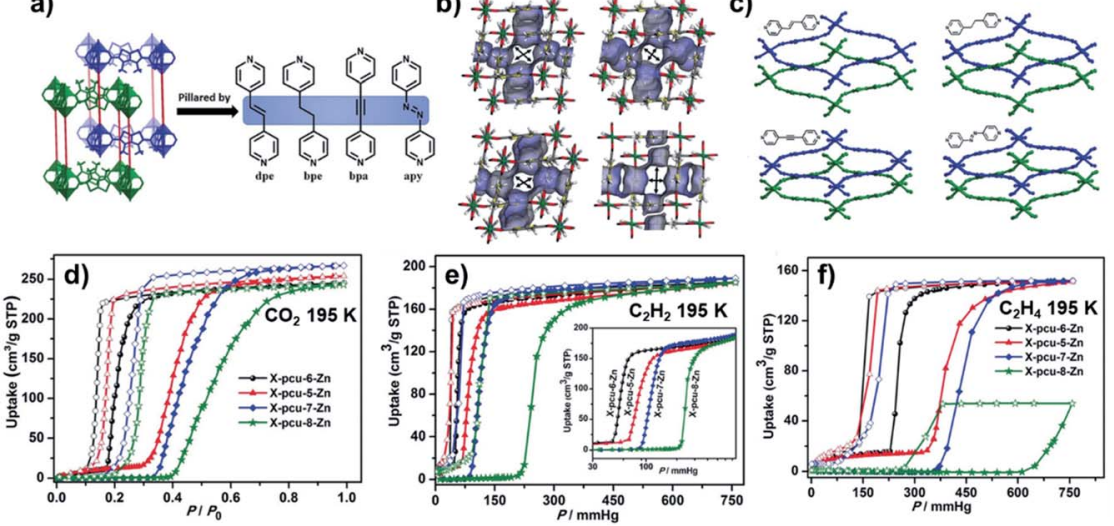

Fig. 11 (a) The two-fold interpenetrated structures of $X-p c u-n-Z n$; (b) as-synthesised "open" phases, X-pcu- $n-Z n-\alpha$; (c) activated "closed" phases, X-pcu- $n-Z n-\beta$; (d-f) $\mathrm{CO}_{2}$, $\mathrm{C}_{2} \mathrm{H}_{2}$ and $\mathrm{C}_{2} \mathrm{H}_{4}$ sorption isotherms on X-pcu- $n-\mathrm{Zn}-\beta$ at $195 \mathrm{~K}$. Reproduced from ref. 147 with permission; copyright: 2019, John Wiley \& Sons, Inc. 
guest-accessible volume. Both PLCNs were found to exhibit complicated structural transformations through solvent exchange, heating, vacuum and gas sorption processes. Interestingly, a rare example of "shape memory" was observed for X-pcu-3-Zn and X-pcu-1-Zn, which exhibited irreversible phase transitions. The only other reported example of this phenomenon was for $\left[\mathrm{Cu}_{2}(\mathrm{bdc})_{2}(\mathrm{bpy})\right]^{.93}$

A second diverse class of PLCNs is exemplified by the SIFSIX- $n$-M family of general formula $\left[\mathrm{M}(\mathrm{L})_{2}\left(\mathrm{SiF}_{6}\right)\right](\mathrm{M}=$ divalent transition metal ions, $\mathrm{L}=\mathrm{N}$-donor ditopic ligands). ${ }^{6}$ This family is diverse in composition since the SIFSIX pillar can be replaced by other fluorinated divalent anions such as $\mathrm{TiF}_{6}{ }^{2-}, \mathrm{GeF}_{6}{ }^{2-}$ and $\mathrm{SnF}_{6}{ }^{2-}$ and there are numerous $\mathrm{N}$-donor linkers available. A difference between the SIFSIX- $n$-M and DMOF- 1 families is that N-donor ligands act as linkers in the former whereas they serve as pillars in the latter. Cationic sql layers in the SIFSIX$n$-M family are charge balanced by anionic pillars. The SIFSIX- $n$-M family is of particular interest because several members have been reported to exhibit benchmark separation performances towards a variety of gas mixtures. ${ }^{\mathbf{1 9 6 , 1 9 7}}$ Whereas SIFSIX- $n-\mathrm{M}$ sorbents generally remain rigid during sorption cycles, rotation of linkers can cause inflections in gas adsorption isotherms. ${ }^{\mathbf{1 9 8 , 1 9 9}}$ Recently, our group introduced the first switching SIFSIX- $n-\mathrm{M}$ PLCN, $\left[\mathrm{Cu}(\mathrm{L})_{2}\right.$ $\left(\mathrm{SiF}_{6}\right)$ ] (SIFSIX-23-Cu, L = 1,4-bis(1-imidazolyl)benzene), which was found to exhibit dramatic structural distortions. ${ }^{151}$ Unlike previous SIFSIX- $n$-M sorbents, the SIFSIX pillars in SIFSIX-23-Cu adopt a cis-bridging mode (Fig. 12a and b) and the sql layers undulate thanks to the "V"-shaped L(syn) linker ligands (Fig. 12c). Desolvation induces SIFSIX-23-Cu to undergo structural transformations involving multiple intermediate phases (SIFSIX-23-Cu- $\gamma 1,-\gamma 2,-\gamma 3$ ) prior to forming a solvent-free closed phase, SIFSIX-23-Cu- $\beta 1$ (Fig. 12d). $\mathrm{N}_{2}$ and $\mathrm{CO}_{2}$ sorption on SIFSIX-23-Cu- $\beta 1$ reveal type $\mathrm{F}-\mathrm{IV}^{\mathrm{s}}$ and type $\mathrm{F}-\mathrm{IV}^{\mathrm{m}}$ isotherms,

a)

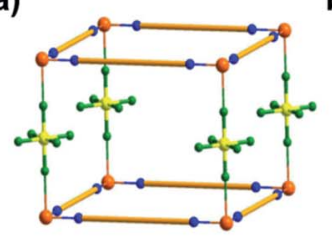

b)

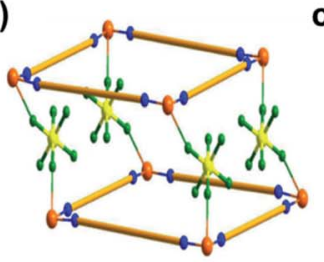

c)

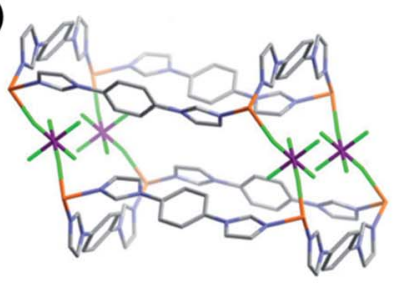

d)

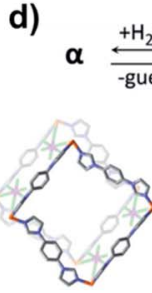

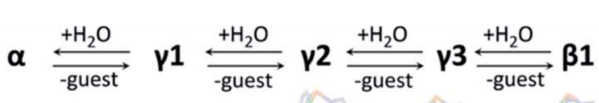

e)

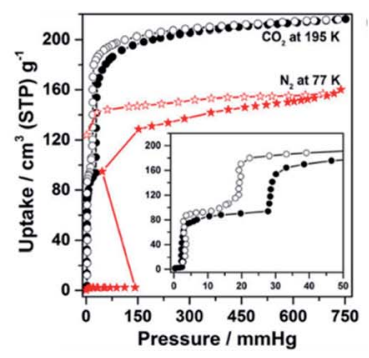

Fig. 12 Schematic diagrams of (a) traditional SIFSIX- $n-M$ networks with trans-bridging SIFSIX pillars and (b) SIFSIX-23-Cu with cis-bridging SIFSIX pillars; (c) coordination mode and geometry in SIFSIX-23-Cu; (d) reversible structural transformations in SIFSIX-23-Cu; (e) $\mathrm{N}_{2}(77 \mathrm{~K})$ and $\mathrm{CO}_{2}(195 \mathrm{~K})$ sorption isotherms of SIFSIX-23-Cu. Reproduced from ref. 151 with permission; copyright: 2020, American Chemical Society. 
respectively (Fig. 12e). SIFSIX-23-Cu is one of the few switching CNs that exhibits $>200 \mathrm{~cm}^{3} \mathrm{~g}^{-1}$ gas uptake and good recyclability ( $>40$ sorption cycles). SIFSIX-23-Cu was also found to be stable in water for at least one year.

2.1.3 Diamondoid CNs. Diamondoid CNs feature dia topology and are amongst the earliest and most comprehensively studied CNs. They are also highly amenable to crystal engineering. ${ }^{\mathbf{1 3 , 1 4 , 2 0 0 , 2 0 1}}$ Interpenetration in diamondoid CNs tends to reduce surface area but can enhance rigidity. ${ }^{202}$ Nevertheless, structural flexibility was observed in the 2-fold interpenetrated diamondoid $\mathrm{CN}$ [ $\left.\operatorname{In}(\mathrm{ABDC})_{2}\right]$ (SHF-61, ABDC = 2-aminobenzene-1,4-dicarboxylate) with continuous breathing/ swelling behaviour during desolvation/solvation. ${ }^{203}$ This is a rare phenomenon that was previously observed in MIL-88 CNs. ${ }^{56,57}$ The 8 -fold interpenetrated diamondoid CN [Zn(oba)(pip)] (JUK-8), which is based on 4,4'-oxybis(benzenedicarboxylate) (oba) and 4-pyridyl functionalised benzene-1,3dicarbohydrazide (pip) linkers, exhibited switching upon exposure to $\mathrm{H}_{2} \mathrm{O}$ and $\mathrm{CO}_{2}{ }^{154}$

Recently, our group reported a flexible diamondoid $\mathrm{CN}$ [NiL $\mathrm{N}_{2}$, X-dia-1-Ni, which is based upon a mixed N/O-donor ligand, 4-(4-pyridyl)-biphenyl-4carboxylic acid (HL). ${ }^{67}$ Despite 6-fold interpenetration, the accessible void volume in X-dia-1-Ni is $49 \%$ thanks to the mode of interpenetration and the rectangular channels sustained by ligand L (Fig. 13a-d). X-dia-1-Ni was observed to undergo single-crystal-to-single-crystal (SCSC) transformations through solvent exchange with $\mathrm{CH}_{2} \mathrm{Cl}_{2}$ and transform to its closed phase X-dia-1-Ni-c1 by heating under vacuum (Fig. 13e). $77 \mathrm{~K} \mathrm{~N}_{2}$ sorption indicated that X-dia-1-Ni-c1 is nonporous whereas $195 \mathrm{~K} \mathrm{CO}_{2}$ sorption revealed multiple steps in both the adsorption and desorption branches. These profiles indicate reversible structural

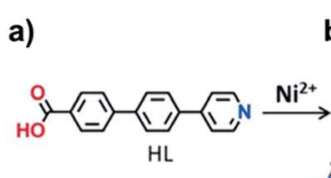

b)

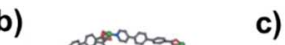

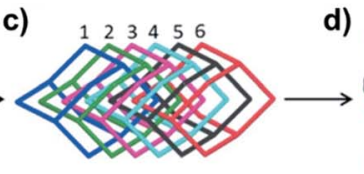

6-fold dia nets

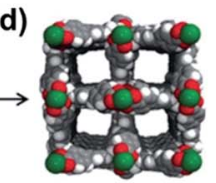

$\mathrm{X}$-dia-1-Ni

f)

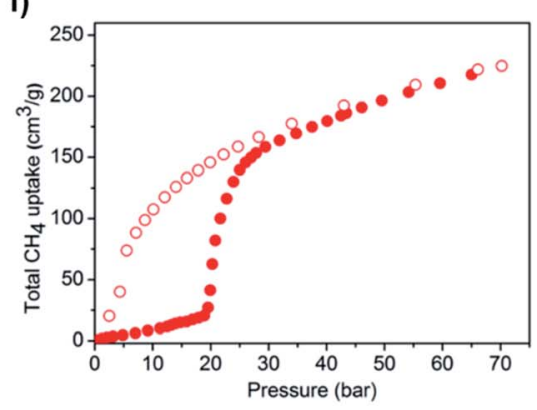

e)

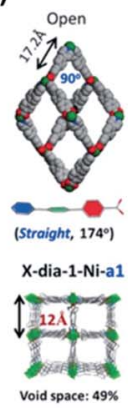

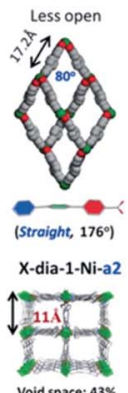

Void space: $43 \%$
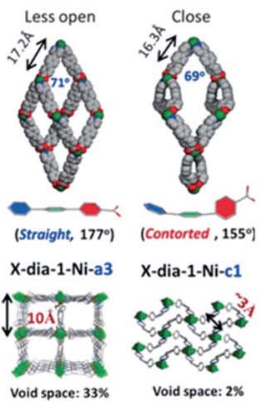

Fig. 13 (a) Structure of 4-(4-pyridyl)-biphenyl-4-carboxylic acid (HL); (b) adamantanoid cage in X-dia-1-Ni; (c) 6-fold interpenetrated dia nets in X-dia-1-Ni; (d) rectangular channels of $\mathrm{X}$-dia-1-Ni viewed along the $c$-axis; (e) single crystal structures of the porous (a1, a2, a3) and nonporous (c1) phases of $\mathrm{X}$-dia-1-Ni; (f) high pressure $\mathrm{CH}_{4}$ sorption isotherm of X-dia-1-Ni at $298 \mathrm{~K}$. Reproduced from ref. 67 with permission; copyright: 2018, John Wiley \& Sons, Inc. 
changes between closed and open phases. Interestingly, the $\mathrm{CH}_{4}$ adsorption isotherm measured at $298 \mathrm{~K}$ (Fig. 13f) revealed a type $\mathrm{F}-\mathrm{IV}^{\mathrm{S}}$ isotherm that combined an appropriate switching pressure (5-35 bar) and high saturation uptake $\left(>200 \mathrm{~cm}^{3} \mathrm{~g}^{-1}\right)$. These metrics made X-dia-1-Ni only the second flexible CN after $\mathrm{Co}(\mathrm{bdp})$ to exhibit such a high working capacity for $\mathrm{CH}_{4} \cdot \mathrm{Co}(\mathrm{bdp})$ is discussed in the following section.

2.1.4 M(bdp) family. Switching CNs usually exhibit only two phases (e.g. one open phase and one closed phase) and their structural transformations are typically induced by polar gases such as $\mathrm{CO}_{2}$ and $\mathrm{C}_{2} \mathrm{H}_{2}$ or polar solvents. Multiple phase transitions induced by nonpolar molecules such as $\mathrm{H}_{2}$ and $\mathrm{N}_{2}$ are somewhat rare. Long et al. reported that a 3D switching CN Co(bdp) (Fig. 14a, bdp $=1,4$-benzenedipyrazolate), ${ }^{74,101-103}$ exhibits an unusual five-step $\mathrm{N}_{2}$ sorption isotherm at $77 \mathrm{~K}$ (Fig. 14b). A combination of in situ PXRD and molecular simulation studies revealed that the activated "closed" phase, Co(bdp)-dry, transformed to its fully "open" phase via three distinct intermediate phases (Fig. 14c). In addition, $\mathrm{H}_{2}$ sorption on $\mathrm{Co}(\mathrm{bdp})$-dry revealed a phase transformation which was not seen in other switching CNs. ${ }^{101}$ Most importantly, Co(bdp)-dry exhibits a stepped type $\mathrm{F}-\mathrm{IV}^{\mathrm{S}}$ isotherm when exposed to $\mathrm{CH}_{4}$ (Fig. 14d).$^{74}$ The gate adsorption and desorption pressures are $c a .15$ and 5 bar, respectively, suitable for $\mathrm{CH}_{4}$ storage and delivery in the context of vehicular transport (5-35 bar). High uptake and the right type of F-IV isotherm profile made $\mathrm{Co}$ (bdp) the benchmark for $\mathrm{CH}_{4}$ working capacity $\left(c a .200 \mathrm{~cm}^{3} \mathrm{~cm}^{-3}\right.$ ). The Fe

a)

b)
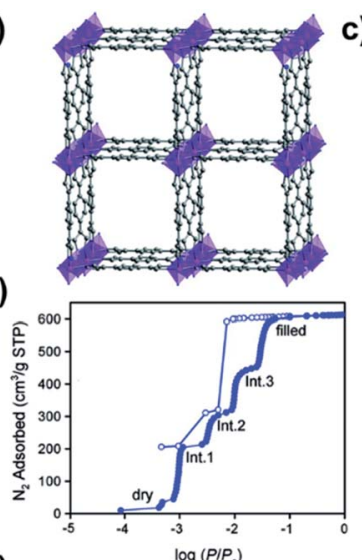

d)

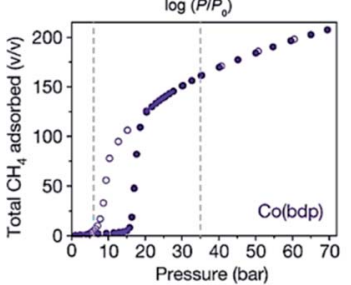

c)

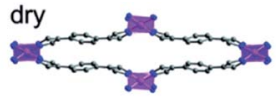

Int.1
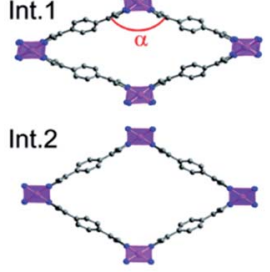

Int.3
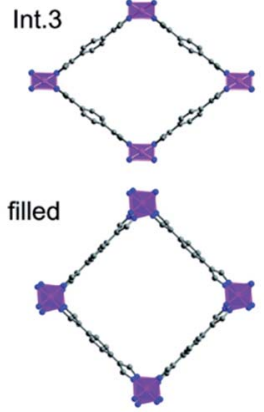

Fig. 14 (a) Crystal structure of as-synthesised $\mathrm{Co}(\mathrm{bdp})$; (b) $\mathrm{N}_{2}$ sorption isotherms of $\mathrm{Co}(\mathrm{bdp})$-dry at $77 \mathrm{~K}$; (c) phase transition during $\mathrm{N}_{2}$ sorption; and (d) $\mathrm{CH}_{4}$ sorption isotherms of Co(bdp)-dry at $298 \mathrm{~K}$. Reproduced from ref. 74 and 102 with permission; copyrights: 2015, Springer Nature and 2010, American Chemical Society. 
analogue, $\mathrm{Fe}(\mathrm{bdp})$, was also found to exhibit a type F-IV ${ }^{\mathrm{s}}$ isotherm but with a much higher switching pressure, highlighting the profound impact that metal centers can exert on switching pressures. In contrast, the $\mathrm{Zn}$ and $\mathrm{Ni}$ analogues, $\mathrm{Zn}(\mathrm{bdp})$ and $\mathrm{Ni}(\mathrm{bdp})$, were only found to exhibit type I gas sorption isotherms. ${ }^{\mathbf{2 0 4}}$ Furthermore, ligand functionalization in $\mathrm{Co}(\mathrm{bdp})$ can be used to tune the switching pressures. ${ }^{133}$

\subsection{Examples of 2D switching CNs}

2.2.1 Square lattice (sql) CNs. 2D CNs may exhibit switching through claylike intercalation. One would intuitively anticipate that such a switching mechanism is facile because the attractive forces between layers are relatively weak and little strain upon the $\mathrm{CN}$ is likely to be required. Square lattice (sql) CNs are quite prevalent and account for nearly half of reported $2 \mathrm{D} \mathrm{CNs} .{ }^{205} \mathrm{~A}$ well-studied family of sql CNs is comprised of octahedral metal ions (M), axial counter anions (A) and linear linker ligands (L). ${ }^{206}$ When $\mathrm{M}: \mathrm{L}$ is $1: 2$, sql CNs of general formula $\left[\mathrm{M}(\mathrm{L})_{2}(\mathrm{~A})_{2}\right] \cdot x$ guest can be formed (Fig. 15). ${ }^{207-209}$ From a crystal engineering perspective, this family of CNs exemplify the "node and linker" strategy first developed by Robson and Hoskins over thirty years ago. ${ }^{13,14}$ An emphasis upon design and structural characterization of sql CNs preceded sorption studies until the ELM (elastic layer-structured MOF) family was investigated..$^{28,59,72,85-90}$

The first reported sorption study on sql CNs was conducted upon $\left[\mathrm{Cu}(\mathrm{bpy})_{2}\right.$ $\left.\left(\mathrm{BF}_{4}\right)_{2}\right], \mathrm{ELM}-11 .^{59}$ In 2001, Kaneko et al. first studied the 1D linear chain CP $\left[\mathrm{Cu}(\mathrm{bpy})\left(\mathrm{BF}_{4}\right)_{2}\left(\mathrm{H}_{2} \mathrm{O}\right)_{2} \cdot\right.$ bpy] (Fig. 16a) ${ }^{28}$ and its activated form, ELM-11, was observed to exhibit phase switching when exposed to $\mathrm{N}_{2}$, Ar and $\mathrm{CO}_{2}$. To our knowledge, this is the first example of type F-IV sorption isotherms in switching CNs. This behaviour was initially attributed to hydrogen bond regulation but there was no structural information concerning the activated form. ${ }^{28}$ It was not until 2006 that the structure of the activated form was determined by synchrotron PXRD to be the sql topology $\mathrm{CN}\left[\mathrm{Cu}(\mathrm{bpy})_{2}\left(\mathrm{BF}_{4}\right)_{2}\right]$ (Fig. 16b).$^{88}$ It was later found that ELM-11 underwent a multi-step rather than single-step phase transition induced by $\mathrm{CO}_{2}$ at 1 bar when the temperature was decreased from 273 to $195 \mathrm{~K}$ (Fig. 16c), ${ }^{86,87}$ revealing a type $\mathrm{F}^{-\mathrm{IV}^{\mathrm{m}}}$ isotherm. The mechanism of the switching behaviour was reinterpreted as expansion/shrinkage between adjacent layers triggered by inclusion of $\mathrm{CO}_{2}$ molecules (Fig. 16d).

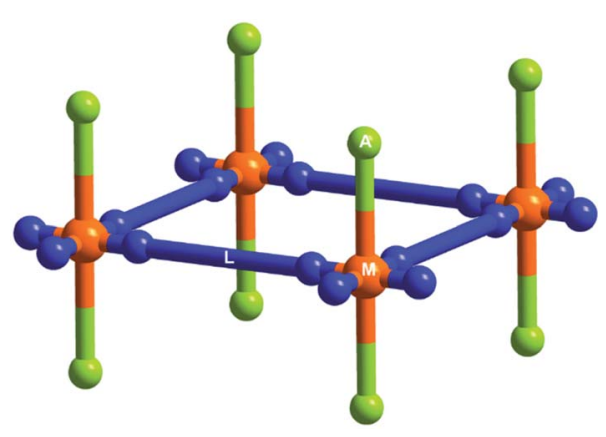

Fig. 15 A schematic illustration of 2D sql CNs. Orange balls: octahedral metal ions (M), lime balls: axial counter anions (A), blue rods: linear linker ligands (L). 
a)
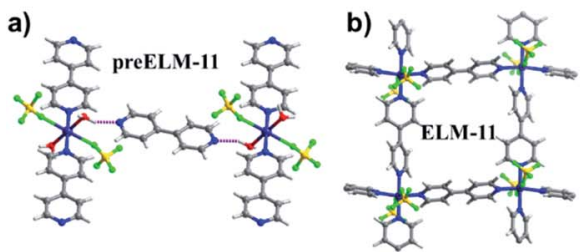

d)

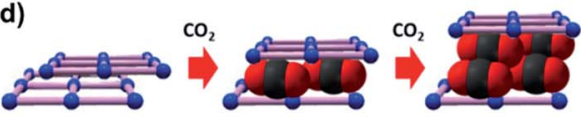

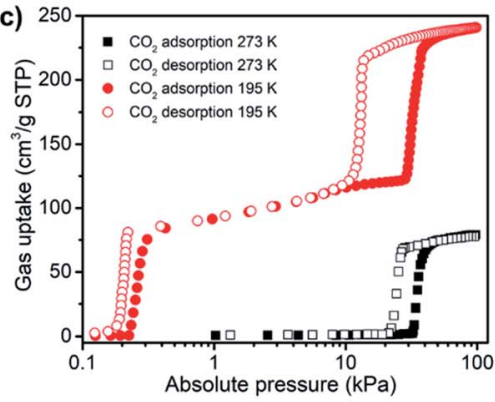

Fig. 16 The structures of (a) preELM-11 and (b) ELM-11; (c) $\mathrm{CO}_{2}$ sorption isotherms of ELM-11 at 195 and $273 \mathrm{~K}$; and (d) illustration of expansion/shrinkage of the adjacent layers in ELM-11. Figure (d) is reproduced from ref. 86 with permission; copyright: 2016, American Chemical Society.

Substitution of the metal cations or counter anions afforded several ELM-11 analogues, ${ }^{59,89}$ including $\left[\mathrm{Cu}(\mathrm{bpy})_{2}(\mathrm{OTf})_{2}\right](\mathrm{ELM}-12){ }^{70}\left[\mathrm{Cu}(\mathrm{bpy})_{2}\left(\mathrm{BF}_{3} \mathrm{CF}_{3}\right)_{2}\right](\mathrm{ELM}-$ 13), ${ }^{153}$ and $\left[\mathrm{Ni}(\mathrm{bpy})_{2}\left(\mathrm{BF}_{4}\right)_{2}\right]$ (ELM-31). ${ }^{104}$ ELM-12 exhibited an open phase after guest removal, possibly because of the "pillaring" role of the OTf ${ }^{-}$anions. With respect to $\mathrm{N}_{2}$ sorption, ELM-12 exhibited a two-step type F-II isotherm distinct from that observed in ELM-11. On the other hand, both ELM-13 and ELM-31 were observed to exhibit type F-IV isotherms like ELM-11 but with different uptakes and switching pressures.

Recently, our group studied the sorption properties of the previously known sql CN $\left[\mathrm{Co}(\mathrm{bpy})_{2}(\mathrm{NCS})_{2}\right],{ }^{208}$ sql-1-Co-NCS, ${ }^{\mathbf{1 4 4 , 1 4 5}}$ which is isostructural to the ELM family. sql-1-Co-NCS is sustained by $\mathrm{Co}(\mathrm{II})$ ions coordinated at equatorial coordination sites to bpy linker ligands with terminal $\mathrm{NCS}^{-}$anions occupying the axial positions. Whereas the $\mathrm{N}_{2}$ uptake of sql-1-Co-NCS at $77 \mathrm{~K}$ was found to be negligible (Fig. 17a), the $195 \mathrm{~K} \mathrm{CO}_{2}$ isotherm was observed to exhibit a type F-IV isotherm. ${ }^{\mathbf{1 4 4}}$ Such an isotherm is consistent with the switching behaviour seen in ELM-11. High-pressure $\mathrm{CO}_{2}$ sorption isotherms of sql-1-Co-NCS were recorded at different temperatures and the relationship between temperature and switching pressure was found to obey the Clausius-Clapeyron equation. In addition, recyclability tests revealed that sql-1-Co-NCS exhibits good recyclability and fast kinetics. $\mathrm{C}_{8}$ aromatic vapour sorption isotherms were also collected on sql-1-CoNCS at 298 K (Fig. 17b). ${ }^{145}$ It was observed that sql-1-Co-NCS switches in the presence of each of the $\mathrm{C}_{8}$ aromatic isomers but with marked differences in terms of adsorption capacity and switching pressure. Single-crystal and powder XRD studies revealed that the interlayer distance in the closed phase $(4.5 \AA)$ increased to $5.4 \AA$ ( $\mathrm{CO}_{2}$ loaded phase) and to $9.2 \AA$ (xylene loaded phase) (Fig. 17c-e), the largest interlayer separation yet reported for bpy-based sql CNs.

2.2.2 Other examples of switching 2D CNs. Kitagawa and co-workers documented several examples of $2 \mathrm{D}$ interdigitated layered CNs and studied their switching properties. ${ }^{65,66}\left[\mathrm{Cu}(\mathrm{dhbc})_{2}\right.$ (bpy)] was prepared from copper nitrate, 2,5dihydroxybenzoic acid (Hdhbc) and 4,4'-bipyridine (bpy). Cu(II) ions are linked by bpy linkers to generate chains that are further linked by two carboxyl groups of dhbc to afford a 2D layer motif. ${ }^{65}$ These layers are mutually interdigitated by the 


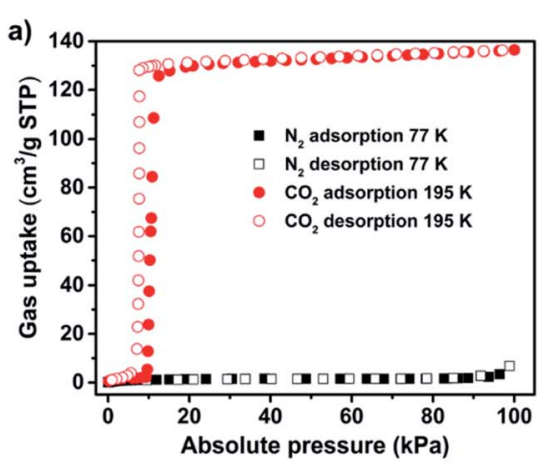

b)
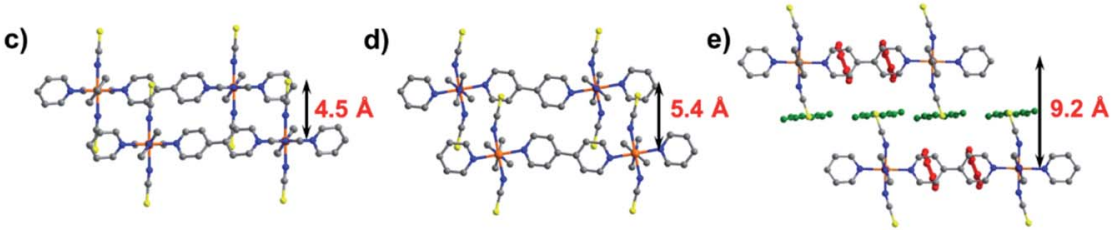

Fig. 17 (a and b) $\mathrm{N}_{2}(77 \mathrm{~K}), \mathrm{CO}_{2}(195 \mathrm{~K})$ and $\mathrm{C}_{8}$ vapour (298 K) sorption isotherms for sql-1Co-NCS; (c-e) layer packing of nonporous, $\mathrm{CO}_{2}$-loaded and xylene loaded phases of sql1-Co-NCS, respectively.

phenolic group of dhbc to generate 1D channels (Fig. 18a). Despite no change to the $\mathrm{Cu}(\mathrm{II})$ coordination environment after activation, the dhbc ligands tilt significantly and transform from cis-mode to trans-mode arrangement which results in layer shrinkage (Fig. 18b) ${ }^{94}$ High pressure $\mathrm{N}_{2}, \mathrm{O}_{2}, \mathrm{CH}_{4}$ and $\mathrm{CO}_{2}$ sorption studies demonstrated that the activated phase of $\left[\mathrm{Cu}(\mathrm{dhbc})_{2}(\mathrm{bpy})\right]$ exhibits a switching effect with type F-IV ${ }^{\mathrm{S}}$ isotherms (Fig. 18c). This study was the first report of a stepped sorption in switching CNs at ambient temperature and high pressure. Adsorbate-dependent switching pressures were observed at 50, 35 and 0.4 bar for $\mathrm{N}_{2}, \mathrm{O}_{2}$ and $\mathrm{CO}_{2}$, respectively.

In 2008, Kitagawa's group introduced another 2D interdigitated CN, [Cd(bpndc)(bpy)] (bpndc = benzophenone-4,4'-dicarboxylate) ${ }^{66}$ SCXRD studies revealed that $\mathrm{Cd}(\mathrm{II})$ nodes are linked by bpndc ligands to produce $1 \mathrm{D}$ double-chain

a)

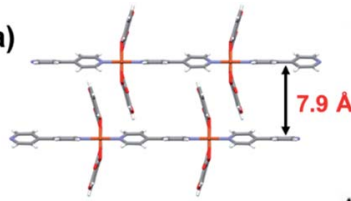

b)

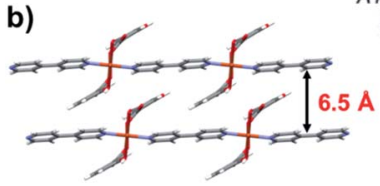

c)

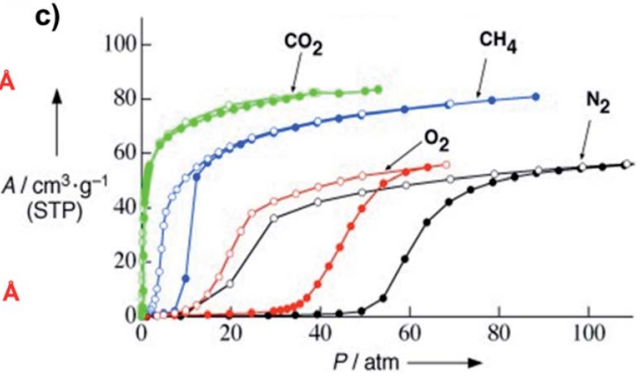

Fig. 18 Crystal structures of (a) open and (b) closed phases of [Cu(dhbc) $2(b p y)]$ and (c) high pressure gas sorption isotherms of its activated phase at $298 \mathrm{~K}$. Figure (c) is reproduced from ref. 65 with permission; copyright: 2003, John Wiley \& Sons, Inc. 
structures of [Cd(bpndc)] (Fig. 19a), which are in turn linked by bpy to afford a 2D bilayer motif (Fig. 19b). As-synthesised [Cd(bpndc)(bpy)] underwent a significant contraction through activation to form its closed phase (Fig. 19c). The sorption isotherms at $90 \mathrm{~K}$ revealed type $\mathrm{F}-\mathrm{IV}^{\mathrm{S}}$ isotherms with different switching pressures for $\mathrm{O}_{2}$, $\mathrm{Ar}$ and $\mathrm{N}_{2}$ of 3.9, 40.1 and $55.3 \mathrm{kPa}$ (Fig. 19d), respectively.

\subsection{Factors that impact switching between phases}

Various factors can influence the flexibility of switching CNs. With respect to extrinsic factors, temperature, pressure and the nature of the adsorbate all impact switching events. Since switching between the closed and open phases is generally a thermodynamic event, low temperature and high pressure tend to promote more facile switching. To this end, in order to screen for switching it is recommended that sorption isotherms are collected at the boiling point of the adsorbate (e.g. $77 \mathrm{~K}$ for $\mathrm{N}_{2}$ or $195 \mathrm{~K}$ for $\mathrm{CO}_{2}$ ). High-pressure gas sorption might be necessary at ambient temperatures. For example, at $298 \mathrm{~K}$ and 1 bar, sql-1-Co-NCS does not exhibit switching upon exposure to $\mathrm{CO}_{2}$. Rather, switching requires either decreasing the temperature to $195 \mathrm{~K}$ or increasing pressure to around 30 bar. ${ }^{144}$ The adsorbate is also a key factor since adsorbate-adsorbent interactions play a role in triggering the phase transformations. ${ }^{106}$ In general, nonpolar gases such as $\mathrm{H}_{2}, \mathrm{Ar}, \mathrm{O}_{2}$ and $\mathrm{N}_{2}$ tend to exhibit relatively weak interactions with most CNs. Hydrocarbons with unsaturated bonds may favour host-guest interactions with decreasing affinity as follows: aromatics $>$ alkynes $>$ alkenes $>$ alkanes. The number of carbon atoms of hydrocarbon adsorbates also influences switching since more carbon atoms generally results in stronger host-guest interactions. However, this empirical rule-of-thumb is limited by the need for suitable pore size and shape in the open phase of switching CNs.

With respect to intrinsic factors, the composition of a $\mathrm{CN}$ is key to enabling and controlling phase transformations including switching. Ligand functionalization has been established as an effective route to fine-tune switching pressure as demonstrated with $\mathrm{Co}(\mathrm{bdp})-\mathrm{X}^{133}$ and MIL-53(Fe)-X. ${ }^{182,183}$ Pillar ligand substitution of X-pcu- $n$-Zn PLCNs was also effective. ${ }^{146,147}$ However, linker ligand
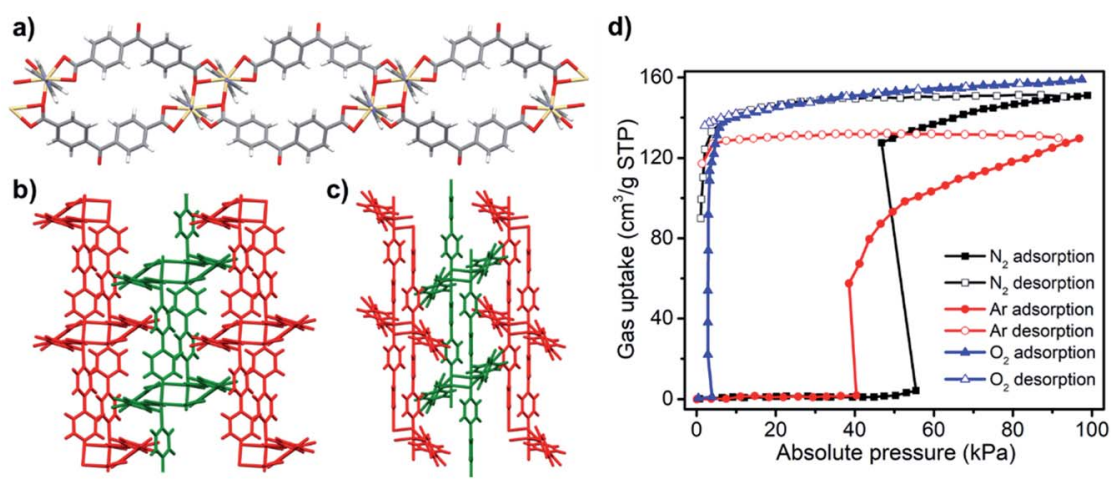

Fig. 19 (a) 1D double chain structure of [Cd(bpndc)]; (b and c) 2D bilayer structure of assynthesised and activated forms of [Cd(bpndc)(bpy)]; (d) $\mathrm{O}_{2}, \mathrm{~N}_{2}$ and Ar sorption isotherms recorded on activated $[\mathrm{Cd}($ bpndc)(bpy)] at $90 \mathrm{~K}$. 
substitution in PLCNs (e.g. DUT-8(Ni) ${ }^{113,114}$ vs. DMOF-1 (ref. 189-191)) can stop switching. This can also occur with metal-node substitution. For three wellstudied families of switching CNs, MIL-53(M), DUT-8(M) and M(dpd), switching was profoundly affected by metal node substitution. Only specific metal nodes, i.e., MIL-53(Fe/Sc), DUT-8(Ni) and Co/Fe(dpd), were observed to exhibit switching behaviour. Particle size can also impact switching behaviour but remains largely understudied. ${ }^{\mathbf{1 4 0 , 1 9 4}}$

\section{Switching mechanisms}

Although switching CNs generally exhibit type F-IV sorption isotherms and may share structural features, switching mechanisms can vary. Most switching CNs crystallize as solvated (open) phases and transform to their desolvated (closed) phases during solvent removal/activation. For some CNs this is the full scope of phases and switching occurs just between the as-synthesized (open) and activated (closed) phases. For other CNs, one or more metastable states (intermediate phases) that are partially open can exist in addition to the closed and fully open phases. To elucidate switching mechanisms we herein analyse the closed and open phases of switching CNs that are structurally characterized (usually by SCXRD). At the molecular level, switching mechanisms can be driven by intranetwork distortions, inter-network interactions or most likely a combination thereof (Fig. 20 and Table 4).$^{38-41}$ Intra-network distortions include ligand motions (Fig. 20a: bending, twisting and rotation), metal node coordination sphere changes (Fig. 20b: deformation and reconstitution/isomerism) and overall intranetwork motions (Fig. 20c: edge bending/straightening and net shearing). Internetwork motions include subnetwork displacements such as interpenetrated net sliding (Fig. 20d) and layered net expansion (Fig. 20e).

Ligand motion is often observed, not just in flexible CNs, but also in rigid CNs. ${ }^{\text {10-212 }}$ When ligand motion occurs in switching CNs it tends to occur over

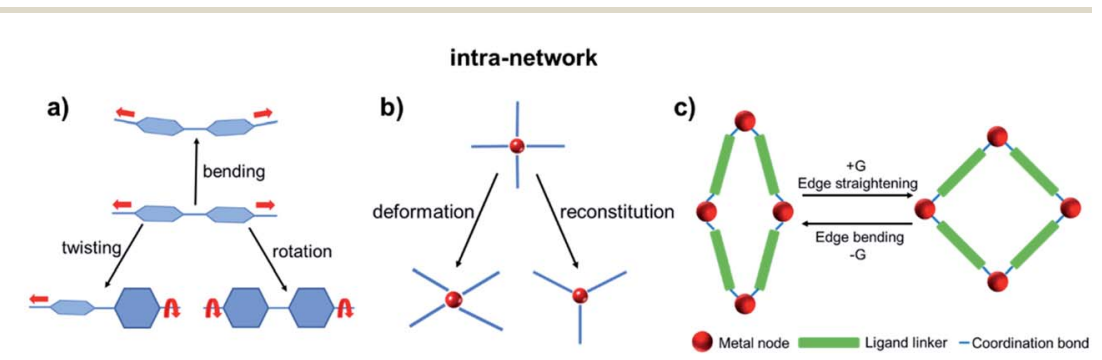

inter-network

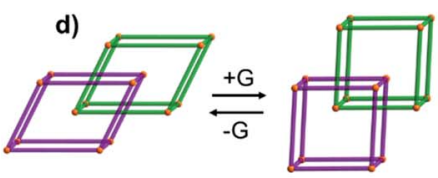

Interpenetrated net sliding e)

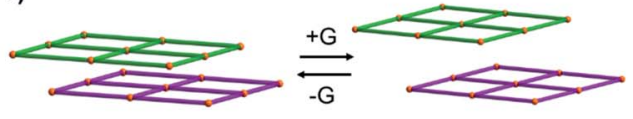

layered net expansion

Fig. 20 Schematic of switching mechanisms driven by intra-network and inter-network changes: (a) ligand motion; (b) metal node motion; (c) overall intra-network motion; (d) interpenetrated net sliding and (e) layered net expansion. 
Table 4 Switching mechanisms of representative switching $\mathrm{CNs}^{a}$

\begin{tabular}{|c|c|c|c|c|c|c|c|c|}
\hline \multirow[b]{4}{*}{ Switching CNs } & \multicolumn{7}{|c|}{ Switching mechanisms } & \multirow[b]{4}{*}{ Ref. } \\
\hline & \multicolumn{5}{|c|}{ Intra-network } & \multicolumn{2}{|c|}{$\begin{array}{l}\text { Inter- } \\
\text { network }\end{array}$} & \\
\hline & \multicolumn{2}{|c|}{$\begin{array}{l}\text { Metal } \\
\text { node }\end{array}$} & \multicolumn{3}{|c|}{ Linker ligand } & \multicolumn{2}{|c|}{ Subnet } & \\
\hline & A & B & $\mathrm{C}$ & $\mathrm{D}$ & $\mathrm{E}$ & $\mathrm{F}$ & $\mathrm{G}$ & \\
\hline MIL-53(Fe) & $x$ & $x$ & $\checkmark$ & $x$ & $x$ & $x$ & $x$ & 106 \\
\hline MOF-508 & $\checkmark$ & $x$ & $\checkmark$ & $x$ & $x$ & $\checkmark$ & $x$ & 97 and 99 \\
\hline DUT-8(Ni) & $\checkmark$ & $x$ & $\checkmark$ & $x$ & $x$ & $x$ & $x$ & 115 \\
\hline$\left[\mathrm{Cu}_{2}(\mathrm{bdc})_{2}(\mathrm{bpy})\right]$ & $\checkmark$ & $x$ & $\checkmark$ & $x$ & $\checkmark$ & $\checkmark$ & $x$ & 93 \\
\hline$\left[\mathrm{Zn}_{2}(\mathrm{tp})_{2}(\mathrm{dfbpb})\right]$ & $x$ & $\checkmark$ & $\checkmark$ & $\checkmark$ & $\checkmark$ & $\checkmark$ & $x$ & 120 \\
\hline X-pcu- $n$-Zn $(n=5-8)$ & $x$ & $x$ & $\checkmark$ & $x$ & $\checkmark$ & $\checkmark$ & $x$ & 146 and 147 \\
\hline $\mathrm{X}$-dia-1-Ni & $x$ & $x$ & $x$ & $\checkmark$ & $\checkmark$ & $\checkmark$ & $x$ & 67 \\
\hline Co(bdp) & $x$ & $x$ & $\checkmark$ & $x$ & $\checkmark$ & $x$ & $x$ & 102 \\
\hline ELM-11 & $x$ & $x$ & $\checkmark$ & $x$ & $\checkmark$ & $x$ & $\checkmark$ & 89 \\
\hline sql-1-Co-NCS & $x$ & $x$ & $\checkmark$ & $x$ & $\checkmark$ & $x$ & $\checkmark$ & 144 and 145 \\
\hline$\left[\mathrm{Cu}(\mathrm{dhbc})_{2}(\mathrm{bpy})\right]$ & $x$ & $x$ & $\checkmark$ & $x$ & $\checkmark$ & $x$ & $\checkmark$ & 65 and 94 \\
\hline$[\mathrm{Cu}($ pyrdc $)(\mathrm{bpp})]$ & $x$ & $\checkmark$ & $x$ & $\checkmark$ & $x$ & $x$ & $\checkmark$ & 96 \\
\hline [Cd(bpndc)(bpy)] & $x$ & $\checkmark$ & $x$ & $x$ & $x$ & $x$ & $\checkmark$ & 66 \\
\hline SIFSIX-23-Cu & $x$ & $x$ & $\checkmark$ & $\checkmark$ & $\checkmark$ & $x$ & $x$ & 151 \\
\hline
\end{tabular}

${ }^{a}$ A: deformation; B: reconstitution; C: rotation; D: bending; E: twisting; F: interpenetrated net sliding; G: layered net expansion.

a relatively large amplitude. Compositional analysis of switching CNs reveals that the most commonly used organic ligands are the linear linkers bpy and bdc, which occur in $c a$. $25 \%$ of switching CNs. The N-donor linker bpy can rotate and twist even without ligand bending, as exemplified by sql CNs such as sql-1-CoNCS (Fig. 21a). ${ }^{\mathbf{1 4 4 , 1 4 5}}$ The O-donor ligand bdc rotates, as exemplified by MIL53(Fe) (Fig. 21b and 7b), ${ }^{106}$ and bending behaviour was reported for DMOF-1. ${ }^{189}$ Ligand rotation is a feature of functionalised MIL-53(Fe) analogues, MIL-53(Fe)-X, whereby the functional groups $\mathrm{X}$ in the closed phases project towards the channels and prevent full contraction. ${ }^{181}$ Ligand rotation and twisting was also reported for Co(bdp) (Fig. 21c) ${ }^{74}$ whereas more extreme ligand bending that could be described as contortion was seen for longer ligands such as pbpc in X-dia-1-Ni (Fig. 13e). ${ }^{67}$

Metal node motion does not always occur in switching CNs. For example, the coordination environments of metal nodes in sql-1-Co-NCS (octahedral geometry), MIL-53(Fe) (octahedral geometry) and $\mathrm{Co}(\mathrm{bdp})$ (tetrahedral geometry) were unchanged in their closed and open phases. Conversely, metal node deformation was observed in the $\left[\mathrm{Zn}_{2}(\mathrm{COO})_{4}\right]$ and $\left[\mathrm{Ni}_{2}(\mathrm{COO})_{4}\right]$ paddle-wheel units of MOF-508 (ref. 97 and 99) and DUT-8(Ni), ${ }^{115}$ respectively (Fig. 10a). Metal node isomerism involving coordination bond breakage remains relatively rare but plays an important role in some switching CNs, e.g. $\left[\mathrm{Cu}(\right.$ pyrdc)(bpp) $],\left[\mathrm{Zn}_{2}(\mathrm{bdc})_{2}(\mathrm{dfbpb})\right]$ and $[\mathrm{Co}(\mathrm{VTTF})]^{96,120,138}$

Intra-network motion can often be attributed to cooperative ligand and metal node motions, e.g. net shearing and edge bending/strengthening (hinge motion) 
a)
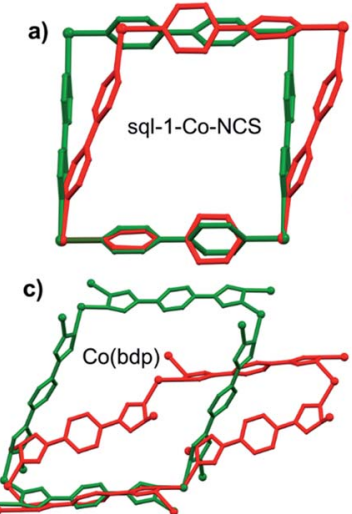

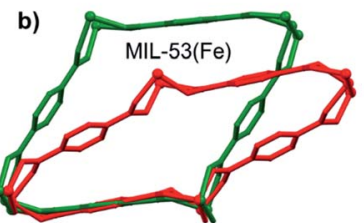

d)

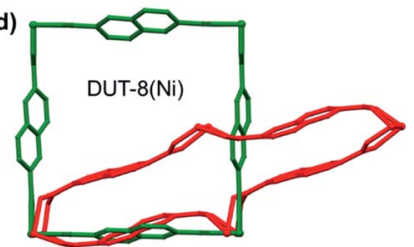

Fig. 21 Overlay comparison of closed (red) and open (green) phases of four switching CNs: (a) sql-1-Co-NCS; (b) MIL-53(Fe); (c) Co(bdp) and (d) DUT-8(Ni).

that arise thanks to nonlinear coordination modes between metal ions and organic ligands. Overall, our analysis indicates that intra-network motions are quite common in switching CNs that feature square or rhombic cavities (Fig. 21). This is presumably attributable to the rhombus being a basic flexible building block of a "truss network", as observed even at the macro scale. ${ }^{213}$ For example, at the macro scale, a common use of "rhombus deformation" in a chemistry lab would be the lab jack. Integration of square or rhombic units into a $\mathrm{CN}$ is likely to be a viable crystal engineering strategy to design new switching CNs from first principles.

Subnetwork displacement is a phenomenon restricted to CNs that comprise individual subnets that interact with each other by weak forces, e.g. hydrogen bonding or van der Waals interactions. This includes interpenetrated net sliding as well as layered net expansion in $3 \mathrm{D}$ and $2 \mathrm{D}$ switching CNs, respectively. Interpenetrated net sliding usually occurs between centered interpenetrated nets (closed phase) and offset interpenetrated nets (open phase), thereby creating voids to accommodate guest molecules as exemplified by 2 -fold interpenetrated PLCNs such as the X-pcu- $n$-Zn family. ${ }^{\mathbf{1 4 6 , 1 4 7}}$ Layered net expansion occurs in $2 \mathrm{D}$ switching CNs thanks to their ability to offer clay-like intercalation of guest molecules as observed in switching sql CNs. ${ }^{\mathbf{1 4 4 , 1 4 5}}$

A question that remains to be answered is why do isostructural CNs exhibit very different structural flexibility and sorption behaviour, e.g. MIL-47 does not exhibit breathing behaviour whereas MIL-53 does? ${ }^{214,215}$ Addressing this matter requires a quantitative understanding of the energy landscape including the energy barriers between multiple phases and the energy derived from host-guest and guest-guest interactions. ${ }^{\mathbf{2 1 6 - 2 1 8}}$ In addition, kinetic factors such as linker rotation dynamics can affect the framework transition, especially across transient phases. ${ }^{219}$ In many cases, the precise mechanisms of phase transformations are beyond the scope of SCXRD, which only provides the static perspective of crystal structures. Further mechanistic insight will likely come through in situ experiments coupled with molecular modeling studies. 


\section{Applications}

\subsection{Gas storage}

Gas storage is one of the most important and well-studied properties of porous CNs. ${ }^{220-223}$ Indeed, we are in the "age of gas"224 and physisorption is recognised as an energy-efficient approach to mitigate the energy footprint associated with traditional compression and liquefaction-based technologies. A variety of gases such as non-polar gases $\left(\mathrm{H}_{2}, \mathrm{O}_{2}, \mathrm{~N}_{2}, \mathrm{Ar}\right.$, Xe), polar gases (CO, NO, $\left.\mathrm{CO}_{2}\right)$ and $\mathrm{C}_{2}-\mathrm{C}_{4}$ light hydrocarbon gases and vapours have been investigated in rigid porous CNs. ${ }^{220-223} 77 \mathrm{~K} \mathrm{~N}_{2}$ sorption serves as the most common characterisation tool to experimentally determine the porosity of an adsorbent. The greenhouse gas $\mathrm{CO}_{2}$ is another extensively studied gas at low (e.g. $195 \mathrm{~K}$ and 1 bar) and high (e.g. $298 \mathrm{~K}$ and 50 bar) temperatures and pressures, driven by the importance of carbon capture from flue gases (bulk) and air (trace). On the other hand, as a relatively inexpensive and clean fuel gas, $\mathrm{CH}_{4}$ is of particular interest and importance given the energy footprints and limitations of liquified and compressed nature gas storage.

Recent studies have demonstrated that switching nonporous CNs that exhibit type F-IV isotherms can enable higher working capacities than physisorbents with type I isotherms as explained above (Fig. 2f). There are several other potential advantages of switching CNs for gas storage. First, since type F-IV isotherms usually exhibit hysteresis between their adsorption and desorption branches, it allows for a gas to be adsorbed at high pressure and stored at relatively low pressure. ${ }^{72}$ Second, switching pressure and temperature follow the ClausiusClapeyron equation, ${ }^{72,86,144}$ which means that switching pressure can be calculated for a given temperature. This enables the selection of a bespoke sorbent that offers optimised parameters for temperature or pressure swing adsorption processes or combinations thereof. Last, but not least, endothermal/exothermal structural expansion/contraction in switching CNs naturally offsets the exothermal/endothermal nature of adsorption/desorption processes, thereby facilitating improved thermal management. ${ }^{7,87}$

As detailed earlier herein, various gases have been studied to determine if they can induce switching in CNs (Table 1). $77 \mathrm{~K} \mathrm{~N}_{2}$ and $195 \mathrm{~K} \mathrm{CO}_{2}$ sorption isotherms are well documented as summarised in Table 5. Thus far, around 20 switching CNs exhibit $>100 \mathrm{~cm}^{3} \mathrm{~g}^{-1} \mathrm{CO}_{2}$ or $\mathrm{N}_{2}$ uptake at cryogenic temperatures and their switching pressures vary from ca. 0.1 to $80 \mathrm{kPa}$ (Fig. 22a and b). DUT-8(Ni) exhibits the highest $\mathrm{N}_{2}\left(670 \mathrm{~cm}^{3} \mathrm{~g}^{-1}\right)$ and $\mathrm{CO}_{2}\left(590 \mathrm{~cm}^{3} \mathrm{~g}^{-1}\right)$ uptakes yet reported at 77 and $195 \mathrm{~K}$, respectively. ${ }^{114}$ However, at $298 \mathrm{~K}$, DUT-8(Ni) adsorbs negligible $\mathrm{N}_{2}$ and only $58 \%$ of its saturation $\mathrm{CO}_{2}$ uptake $\left(345 \mathrm{~cm}^{3} \mathrm{~g}^{-1}\right)$ at 50 bar. For $\mathrm{CH}_{4}$, DUT-8(Ni) was found to exhibit a characteristic type I isotherm and adsorbed only $70 \mathrm{~cm}^{3} \mathrm{~g}^{-1}$ at 50 bar, $298 \mathrm{~K}$. Other switching CNs such as X-pcu- $n$-Zn, ELM-11 and M(bdp) exhibit $>200 \mathrm{~cm}^{3} \mathrm{~g}^{-1}$ uptakes at cryogenic temperatures. With respect to the $\mathrm{X}-$ pcu- $n$-Zn family $(n=5,6,7,8), \mathrm{X}-$ pcu-6-Zn exhibits the lowest switching pressures for $\mathrm{N}_{2}$ and $\mathrm{CO}_{2} \cdot{ }^{147}$ At $298 \mathrm{~K}$, X-pcu- $n$-Zn CNs exhibit negligible $\mathrm{CO}_{2}$ uptake except for the "softest" variant, X-pcu-6-Zn, which adsorbs $50 \mathrm{~cm}^{3} \mathrm{~g}^{-1}$ of $\mathrm{CO}_{2}$ at $33 \mathrm{bar}$. Unsurprisingly, like DUT-8(Ni), high pressure $\mathrm{CH}_{4}$ adsorption isotherms to 50 bar revealed negligible uptake for all four X-pcu- $n$-Zn CNs. ELM-11 exhibits a type F$\mathrm{IV}^{\mathrm{s}}$ isotherm for $\mathrm{N}_{2}$ at $77 \mathrm{~K}$ and a type $\mathrm{F}-\mathrm{IV}^{\mathrm{m}}$ isotherm for $\mathrm{CO}_{2}$ at $195 \mathrm{~K}$ with almost 
Table $5 \mathrm{~N}_{2}$ (77 K, 1 bar), $\mathrm{CO}_{2}\left(195 \mathrm{~K}, 1\right.$ bar) and $\mathrm{CH}_{4}(298 \mathrm{~K})$ sorption parameters for representative switching $\mathrm{CNs}^{a}$

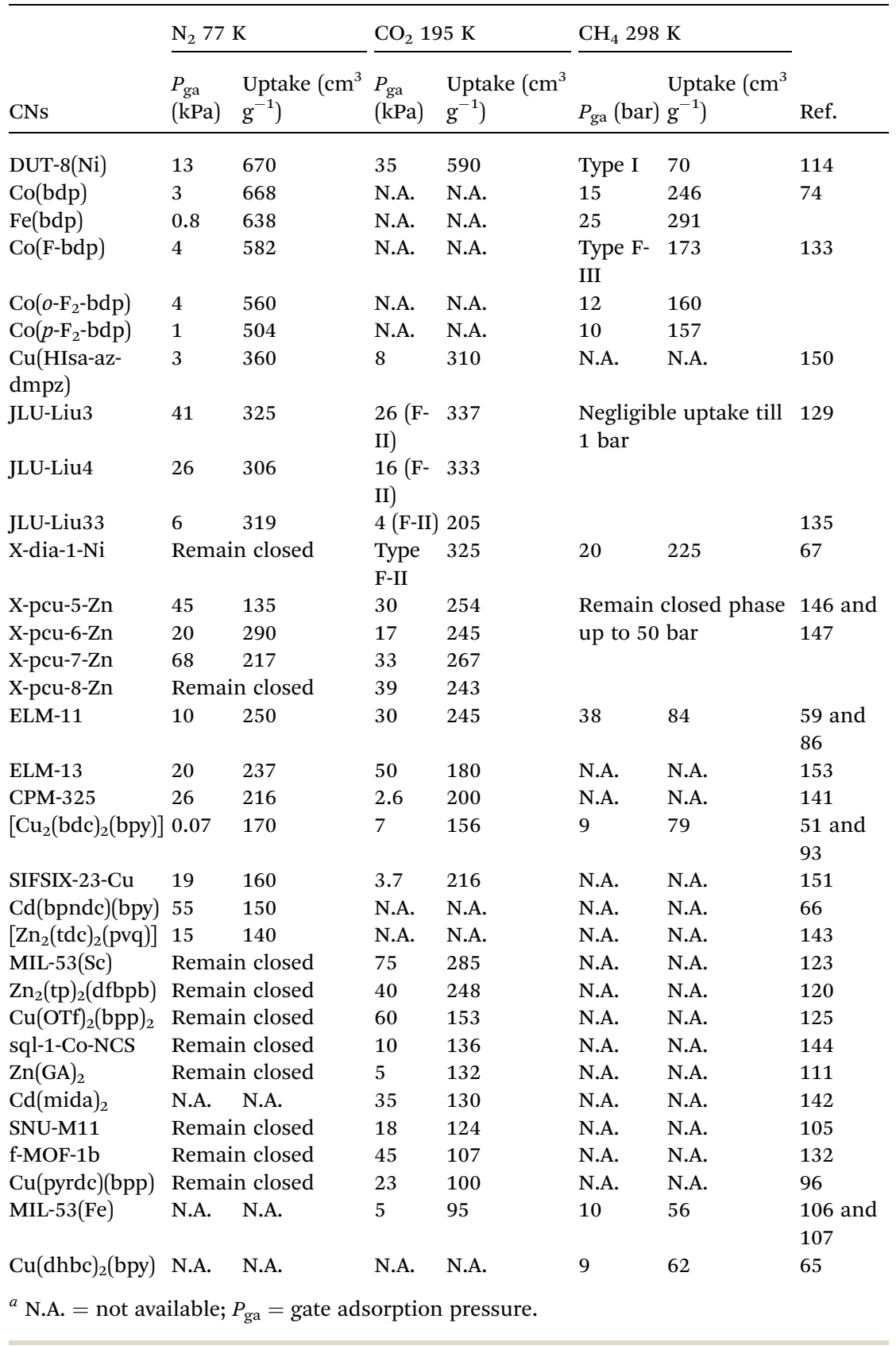

identical saturation uptakes ( $\left.c a .250 \mathrm{~cm}^{3} \mathrm{~g}^{-1}\right) \cdot{ }^{59,86,87}$ High pressure $\mathrm{CO}_{2}$ sorption conducted upon ELM-11 at room temperature produces the type F-IV ${ }^{\mathrm{m}}$ isotherm but with slightly lower uptakes. ${ }^{86}$ High pressure $\mathrm{CH}_{4}$ sorption on ELM-11 at $303 \mathrm{~K}$ revealed a type $\mathrm{F}-\mathrm{IV}^{\mathrm{S}}$ isotherm with $84 \mathrm{~cm}^{3} \mathrm{~g}^{-1}$ uptake, ${ }^{59}$ close to the $\mathrm{CO}_{2}$ uptake 
registered at the first step. This adsorbed volume is comparable to that of active carbon fiber (ACF), but the recovery percentage (i.e., working capacity) of ELM-11 is much higher, ${ }^{59}$ thanks to its isotherm profile. Very recently, ELM-11 (ref. 72) and another switching PLCN, MOF-508, ${ }^{225}$ were studied for a different fuel gas storage application, the storage of the explosive gas acetylene, $\mathrm{C}_{2} \mathrm{H}_{2}$, at ambient temperature. ELM-11 exhibits a four-step type $\mathrm{F}-\mathrm{IV}^{\mathrm{m}}$ isotherm and it can deliver $163 \mathrm{~cm}^{3} \mathrm{~g}^{-1}$ or $174 \mathrm{~cm}^{3} \mathrm{~cm}^{-3}$ of $\mathrm{C}_{2} \mathrm{H}_{2}$ between the second and third steps. However, the switching pressure at the third step is higher than 2 bar, beyond the safety pressure limit for pure $\mathrm{C}_{2} \mathrm{H}_{2}$. It is reasonable to assume that the inclusion and intercalation of $\mathrm{C}_{2} \mathrm{H}_{2}$ into ELM-11 will desensitize $\mathrm{C}_{2} \mathrm{H}_{2}$ but this matter must be verified or a porous monolith might be exploited. In the case of the MOF-508 series, a $\mathrm{C}_{2} \mathrm{H}_{2}$ working capacity of $106 \mathrm{~cm}^{3} \mathrm{~cm}^{-3}$ can be delivered under a relatively narrow pressure range $(70-120 \mathrm{kPa})$. Compared to the benchmark rigid CNs which are more suited for $\mathrm{C}_{2} \mathrm{H}_{2}$ sequestration rather than $\mathrm{C}_{2} \mathrm{H}_{2}$ storage/delivery, ${ }^{72}$ these two reports underline the high upside potential of switching CNs for practical $\mathrm{C}_{2} \mathrm{H}_{2}$ storage.

The switching pressure, one of the two most critical parameters for utility in the context of gas storage, is strongly affected by temperature. For example, the $\mathrm{CO}_{2}$ switching pressure for sql-1-Co-NCS at $195 \mathrm{~K}$ is 0.1 bar but it increases to 26.7 bar at 298 K. ${ }^{144}$ The multi-step switching nature of ELM-11 was overlooked for some time until low-temperature or high-pressure gas sorption isotherms were collected. ${ }^{72,86}$ Although the switching pressure for a given adsorbate can be accurately calculated using the Clausius-Clapeyron equation, once the phase transformation enthalpy is determined, it is difficult to predict the switching pressure across a range of adsorbates. For instance, it is a challenge to quantitatively predict the $\mathrm{CH}_{4}$ switching pressure even if we know the $\mathrm{N}_{2}$ and/or $\mathrm{CO}_{2}$ switching pressures of a given CN. Thus far, most switching CNs that exhibit high $\mathrm{N}_{2}$ and/or $\mathrm{CO}_{2}$ uptake at low (e.g. cryogenic) temperatures exhibit low or negligible $\mathrm{CH}_{4}$ uptake at higher temperatures and pressures. This is likely because $\mathrm{CH}_{4}$ tends to form relatively weak interactions with most CNs, especially compared to $\mathrm{CO}_{2}$. The switching pressure of $\mathrm{CH}_{4}$ is expected to be much higher than that of $\mathrm{N}_{2}$ or $\mathrm{CO}_{2}$ at the same conditions and usually falls beyond the measurement limits of most studies reported in the literature.

With respect to methane storage, there are currently $<10$ switching CNs with $\mathrm{CH}_{4}$ uptake measured at $298 \mathrm{~K}$ and only three (Co(bdp), $\mathrm{Fe}(\mathrm{bdp})$ and X-dia-1-Ni) exhibit $>200 \mathrm{~cm}^{3} \mathrm{~g}^{-1} \mathrm{CH}_{4}$ uptake (Fig. 22c). ${ }^{67,74}$ Considering its relevance to adsorbed natural gas (ANG) storage, ${ }^{226-233}$ the working capacity is typically determined as the quantity of NG that is deliverable between 5-35 or 5-65 bar, pressure ranges that are relevant for commercial combustion engines. In this context, $\mathrm{Co}(\mathrm{bdp})$ and $\mathrm{Fe}(\mathrm{bdp})$ would be expected to deliver around $100 \%$ of the stored NG thanks to their type F-IV isotherms. ${ }^{74}$ To put this in context, rigid CNs that exhibit benchmark gravimetric uptake (e.g. $>500 \mathrm{~cm}^{3} \mathrm{~g}^{-1}$ ) tend to have much lower volumetric working capacities because of their relatively low densities (e.g. $\left.<0.3 \mathrm{~g} \mathrm{~cm}^{-3}\right) .{ }^{233}$ Overall, $\mathrm{Co}(\mathrm{bdp})$ and $\mathrm{Fe}(\mathrm{bdp})$ exhibit comparable or superior volumetric working capacities $\left(\sim 200 \mathrm{~cm}^{3} \mathrm{~cm}^{-3}\right)$ compared to the benchmark rigid CNs (Fig. 22d), and meet the early DOE (U.S. Department of Energy) target for volumetric $\mathrm{CH}_{4}$ uptake $\left(180 \mathrm{~cm}^{3} \mathrm{~cm}^{-3}\right)$. Unfortunately, these working capacities remain well below the current DOE target of $263 \mathrm{~cm}^{3} \mathrm{~cm}^{-3}\left(350 \mathrm{~cm}^{3} \mathrm{~cm}^{-3}\right.$ considering $c a .25 \%$ packing loss). ${ }^{234}$ Indeed, regardless of structural rigidity or 
a)

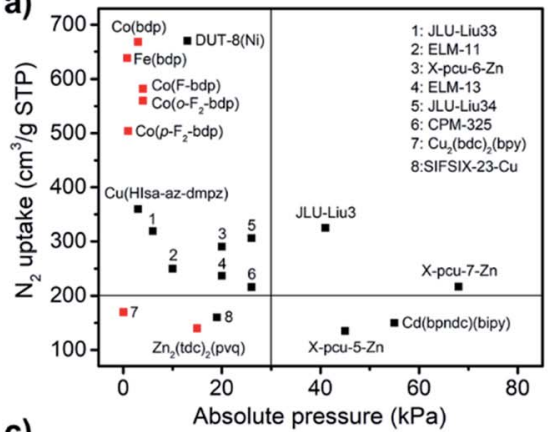

c)

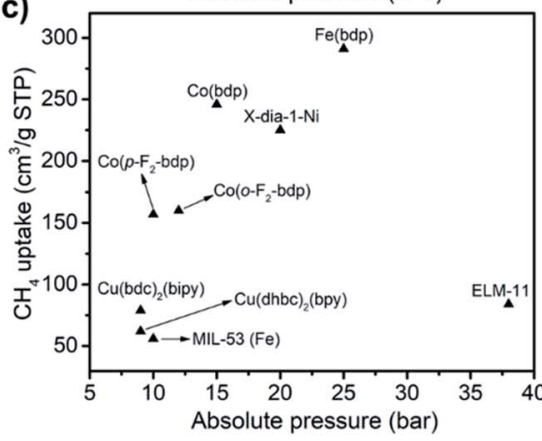

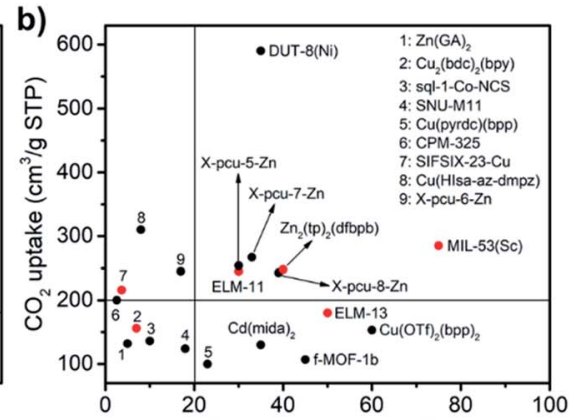

d)

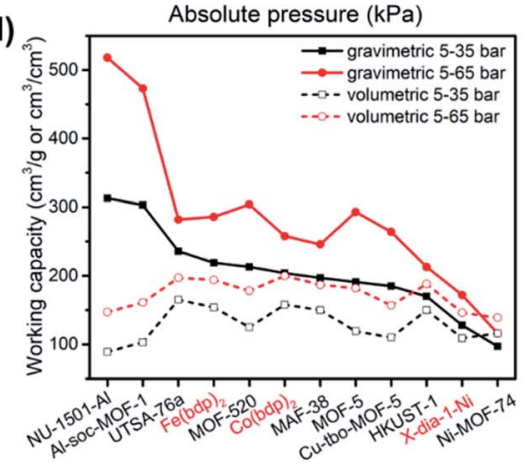

Fig. 22 Comparison of switching CNs with respect to (a) $\mathrm{N}_{2}(77 \mathrm{~K})$, (b) $\mathrm{CO}_{2}(195 \mathrm{~K})$ and (c) $\mathrm{CH}_{4}(298 / 303 \mathrm{~K})$ sorption. Black and red symbols denote $\mathrm{CNs}$ with type $\mathrm{F}-\mathrm{IV}^{\mathrm{s}}$ and $\mathrm{F}-\mathrm{IV} \mathrm{m}$ isotherms respectively. For type $\mathrm{F}-\mathrm{IV}^{\mathrm{m}}$ isotherms, only the switching pressures of the last step are shown. (d) Comparison of gravimetric and volumetric working capacities for $\mathrm{CH}_{4}$ at $298 \mathrm{~K}$ between current benchmarks for switching and rigid CNs.

flexibility, there is no adsorbent that yet meets the ambitious target for methane storage. Accordingly, development of new switching CNs with improved uptakes, the right switching pressures and proper densities is needed to properly exploit their intrinsically advantageous isotherms.

\subsection{Separations}

Separations are of industrial relevance since most commodities are obtained as mixtures and require further purification steps prior to downstream processing and utilisation. ${ }^{235-241}$ Unfortunately, the energy footprint of separation/ purification is generally high and currently represents $\sim 15 \%$ of the global energy consumption because of our reliance upon energy-intensive separation methods such as distillation, evaporation, chemisorption, and crystallization. ${ }^{242}$ Given that a three-fold increase in demand for commodities is projected to occur by $2050,{ }^{224}$ more energy-efficient purification technologies are urgently required. In this context, adsorptive separation using porous solids is increasingly recognised as a promising alternative to traditional methods. Purification of a wide range of mixtures, from gaseous (e.g. $\mathrm{CH}_{4} / \mathrm{CO}_{2}, \mathrm{CH}_{4} / \mathrm{N}_{2}, \mathrm{C}_{2} \mathrm{H}_{2} / \mathrm{CO}_{2}, \mathrm{C}_{2} \mathrm{H}_{2} / \mathrm{C}_{2} \mathrm{H}_{4}$ / $\mathrm{C}_{2} \mathrm{H}_{6}, \mathrm{C}_{3} \mathrm{H}_{4} / \mathrm{C}_{3} \mathrm{H}_{6} / \mathrm{C}_{3} \mathrm{H}_{8}$ ) to vapour and liquid forms (e.g. $\mathrm{C}_{5}, \mathrm{C}_{6}$ alkanes and $\mathrm{C}_{7}, \mathrm{C}_{8}$ aromatics) have been extensively studied using rigid porous $\mathrm{CNs}^{235-241}$ 


\begin{tabular}{|c|c|c|c|c|c|}
\hline Switching CNs & Mixtures & Separation performance & Methods & Conditions & Ref. \\
\hline \multirow[t]{3}{*}{ ELM-11 } & \multirow[t]{2}{*}{$\mathrm{CO}_{2} / \mathrm{CH}_{4}$} & $S_{\mathrm{CO}_{2} / \mathrm{CH}_{4}}: 31$ & \multirow[t]{7}{*}{ BT $(50: 50)$} & $298 \mathrm{~K}, 20 \mathrm{bar}$ & 128 \\
\hline & & $S_{\mathrm{CO}_{2} / \mathrm{CH}_{4}}: 66.7$ & & $273 \mathrm{~K}, 1$ bar & \\
\hline & $\mathrm{CH}_{4} / \mathrm{N}_{2}$ & $S_{\mathrm{CH}_{4} / \mathrm{N}_{2}}: 8.7$ & & $195 \mathrm{~K}, 20 \mathrm{bar}$ & \\
\hline \multirow[t]{4}{*}{$\mathrm{Cu}(\mathrm{dhbc})_{2}$ (bpy) } & $\mathrm{CO}_{2} / \mathrm{CH}_{4}$ & $S_{\mathrm{CO}_{2} / \mathrm{CH}_{4}}: 28.9$ & & $298 \mathrm{~K}, 10 \mathrm{bar}$ & \\
\hline & & $S_{\mathrm{CO}_{2} / \mathrm{CH}_{4}}: 53.4$ & & $273 \mathrm{~K}, 1 \mathrm{bar}$ & \\
\hline & $\mathrm{CH}_{4} / \mathrm{N}_{2}$ & $S_{\mathrm{CH}_{4} / \mathrm{N}_{2}}: 5.5$ & & $273 \mathrm{~K}, 20 \mathrm{bar}$ & \\
\hline & & $S_{\mathrm{CH}_{4} / \mathrm{N}_{2}}: 10.3$ & & $195 \mathrm{~K}, 1 \mathrm{bar}$ & \\
\hline \multirow[t]{5}{*}{ ELM-11 } & $\mathrm{C}_{2} \mathrm{H}_{2} /$ & $S_{\mathrm{CO}_{2} / \mathrm{CH}_{4}}: 10^{8}$ to $10^{9}$ & IAST & $298 \mathrm{~K}, 1$ bar & 85 \\
\hline & $\mathrm{C}_{2} \mathrm{H}_{4}$ & & $(50: 50)$ & & \\
\hline & & $S_{\mathrm{CO}_{2} / \mathrm{CH}_{4}}: 10-100$ & $\begin{array}{l}\text { IAST } \\
(10: 90)\end{array}$ & & \\
\hline & & $\mathrm{C}_{2} \mathrm{H}_{2}$ preference & $\mathrm{BT}(50: 50)$ & & \\
\hline & & & BT $(10: 90)$ & & \\
\hline \multirow[t]{4}{*}{ ELM-13 } & & $S_{\mathrm{CO}_{2} / \mathrm{CH}_{4}}: 10^{4}$ to $10^{5}$ & $\begin{array}{l}\text { IAST } \\
(50: 50)\end{array}$ & & \\
\hline & & $S_{\mathrm{CO}_{2} / \mathrm{CH}_{4}}: 10^{4}$ to $10^{5}$ & $\begin{array}{l}\text { IAST } \\
(10: 90)\end{array}$ & & \\
\hline & & $\mathrm{C}_{2} \mathrm{H}_{2}$ preference & BT $(50: 50)$ & & \\
\hline & & & BT $(10: 90)$ & & \\
\hline \multirow[t]{4}{*}{ Co(bdp) } & $\mathrm{CO}_{2} / \mathrm{CH}_{4}$ & $\begin{array}{l}\text { Near-perfect selectivity } \\
\text { (exact values not given) }\end{array}$ & $\begin{array}{l}\text { BEA } \\
(46: 54)\end{array}$ & 298 K, 6.7 bar & 103 \\
\hline & & & $\begin{array}{l}\text { BEA } \\
(42: 58)\end{array}$ & $298 \mathrm{~K}, 13.9$ bar & \\
\hline & & & $\begin{array}{l}\text { BEA } \\
(43: 57)\end{array}$ & $298 \mathrm{~K}, 25.3 \mathrm{bar}$ & \\
\hline & & $S_{\mathrm{CO}_{2} / \mathrm{CH}_{4}}: 61$ & BEA $(6: 94)$ & $298 \mathrm{~K}, 58.6$ bar & \\
\hline \multirow[t]{3}{*}{ NJU-Bai8 } & $\mathrm{C}_{3} \mathrm{H}_{6} /$ & $S_{\mathrm{C}_{3} \mathrm{O}_{6} / \mathrm{C}_{3} \mathrm{H}_{8}}: 4.6$ & IAST & $298 \mathrm{~K}, 20 \mathrm{kPa}$ & 78 \\
\hline & $\mathrm{C}_{3} \mathrm{H}_{8}$ & & $(50: 50)$ & & \\
\hline & & $\mathrm{C}_{3} \mathrm{H}_{6}$ preference & BT $(20: 20)$ & $298 \mathrm{~K}, 1$ bar & \\
\hline \multirow{5}{*}{$\begin{array}{l}\text { NTU-65 } \\
\text { (SIFSIX-23-Cu) }\end{array}$} & $\mathrm{C}_{2} \mathrm{H}_{2} /$ & Outlet $>99.95 \% \mathrm{C}_{2} \mathrm{H}_{4}$ & BT (1: 99) & $263 \mathrm{~K}, 1$ bar & 152 \\
\hline & $\mathrm{C}_{2} \mathrm{H}_{4}$ & & & & \\
\hline & $\mathrm{CO}_{2} / \mathrm{C}_{2} \mathrm{H}_{4}$ & & BT $(10: 90)$ & & \\
\hline & $\mathrm{C}_{2} \mathrm{H}_{2} /$ & & BT & & \\
\hline & $\mathrm{CO}_{2} / \mathrm{C}_{2} \mathrm{H}_{4}$ & & $(1: 9: 90)$ & & \\
\hline \multirow[t]{2}{*}{$\mathrm{Co}(\mathrm{VTTE})_{2}$} & $\begin{array}{l}\mathrm{C}_{2} \mathrm{H}_{4} / \\
\mathrm{C}_{2} \mathrm{H}_{6}\end{array}$ & $S_{\mathrm{C}_{2} \mathrm{H}_{4} / \mathrm{C}_{2} \mathrm{H}_{6}}: 5.1$ & $\begin{array}{l}\text { BEA } \\
(10: 90)\end{array}$ & $190 \mathrm{~K}, 1$ bar & 70 \\
\hline & & $S_{\mathrm{C}_{2} \mathrm{H}_{4} / \mathrm{C}_{2} \mathrm{H}_{6}}: 1.9$ & $\begin{array}{l}\text { BEA } \\
(50: 50)\end{array}$ & & \\
\hline ELM-13 & $\mathrm{CO}_{2} / \mathrm{N}_{2}$ & $S_{\mathrm{CO}_{2} / \mathrm{N}_{2}}: 13.3$ & $\begin{array}{l}\text { BEA } \\
(50: 50)\end{array}$ & $273 \mathrm{~K}, 10 \mathrm{bar}$ & 82 \\
\hline \multirow[t]{6}{*}{ sql-1-Co-NCS } & $\mathrm{OX} / \mathrm{MX}$ & $S_{\mathrm{OX} / \mathrm{Mx}}: 7.5$ & $\operatorname{BEA}(1: 1)$ & Room temperature, & 145 \\
\hline & $\mathrm{OX} / \mathrm{PX}$ & $S_{\mathrm{OX} / \mathrm{PX}}: 9.6$ & & liquid phase & \\
\hline & $\mathrm{MX} / \mathrm{PX}$ & $S_{\mathrm{MX} / \mathrm{PX}}: 1.3$ & & & \\
\hline & $\mathrm{OX} / \mathrm{EB}$ & $S_{\mathrm{OX} / \mathrm{EB}}: 60.1$ & & & \\
\hline & $\mathrm{MX} / \mathrm{EB}$ & $S_{\mathrm{MX} / \mathrm{EB}}: 3.8$ & & & \\
\hline & $\mathrm{PX} / \mathrm{EB}$ & $S_{\mathrm{PX} / \mathrm{EB}}: 7.3$ & & & \\
\hline \multirow[t]{3}{*}{ MIL-53(Fe) } & $\mathrm{OX} / \mathrm{MX}$ & $S_{\mathrm{OX} / \mathrm{MX}}: 2.66$ & $\mathrm{BT}(1: 1)$ & $323 \mathrm{~K}, 0.05 \mathrm{M}$ in & 175 \\
\hline & $\mathrm{OX} / \mathrm{PX}$ & $S_{\mathrm{OX} / \mathrm{MX}}: 1.88$ & & heptane & \\
\hline & $\mathrm{MX} / \mathrm{PX}$ & $S_{\mathrm{OX} / \mathrm{MX}}: 1.51$ & & & \\
\hline \multirow[t]{3}{*}{ DynaMOF-100 } & $\mathrm{OX} / \mathrm{PX} /$ & PX preference & QEA & Room temperature, & 60 \\
\hline & $\mathrm{MX} / \mathrm{EB}$ & & $(1: 1: 1: 1)$ & liquid phase & \\
\hline & $\mathrm{ST} / \mathrm{EB}$ & ST preference & $\operatorname{BEA}(1: 1)$ & & \\
\hline
\end{tabular}

${ }^{a}$ BT: breakthrough; IAST: ideal adsorbed solution theory; BEA (QEA): binary (quaternary) equilibrium adsorption. 
Switching nonporous CNs remain underexplored in the context of separation but they are attracting increasing attention as stepwise adsorption can endow switching CNs with high adsorption selectivities, at least in principle (e.g. based on Henry's law and/or IAST calculations). This is especially the case when a single component of a mixture exclusively induces structural transformation(s). However, in practice, separation performances tend to be inferior to the theoretical values derived from pure-component sorption isotherms. This is because of the complexities of dynamic conditions, especially sorption/diffusion kinetics and coadsorption. Switching CNs might also be unsuited for trace gas removal (e.g. $<1000 \mathrm{ppm}$, or $0.1 \%$ ) because the switching pressure is normally well above $0.1 \mathrm{kPa}$ at room temperature. Nevertheless, switching CNs hold promise for adsorptive separation as reflected in some of the benchmark separation performances registered in Table 6. For example, ELM-11 exhibits good selectivity for $\mathrm{CO}_{2}$ over $\mathrm{CH}_{4}(66.7)$ at $273 \mathrm{~K}$ and 1 bar as verified by breakthrough experiments. ${ }^{243}$ Importantly, ELM-11 also retains this $\mathrm{CO}_{2} / \mathrm{CH}_{4}$ separation performance at $298 \mathrm{~K}$ and 20 bar, making it favourable for separation of a $\mathrm{CH}_{4} / \mathrm{CO}_{2}$ stream obtained directly from a natural gas source. Similarly, high-pressure purification of $\mathrm{CH}_{4}$ is also observed in $\mathrm{Co}(\mathrm{bdp})$, which exhibits "near-perfect" selectivity of $\mathrm{CO}_{2}$ over $\mathrm{CH}_{4}$ as confirmed by binary equilibrium adsorption experiments. ${ }^{103}$ Another sql $\mathrm{CN}$, sql-1-Co-NCS, was found to exhibit excellent separation performance towards $\mathrm{C}_{8}$ aromatic isomers, ${ }^{\mathbf{1 4 5}}$ one of the seven separation challenges that could "change the world". ${ }^{242}$ This switching adsorbent layered material (SALMA) is the first sorbent that combines high xylene uptake ( $>50 \mathrm{wt} \%)$ with high selectivity $(>5){ }^{145}$ MIL-53(Fe) also exhibited potential to separate xylene isomers, ${ }^{177}$ but its selectivity was determined to be lower than those of sql-1-Co-NCS and MIL-53(Al). ${ }^{145,244,245}$ Another recent example of a high performing switching CN is NTU-65 (also termed SIFSIX-23-Cu). ${ }^{152}$ Compared to zeolites and rigid CNs, NTU-65 exhibited comparable or superior separation performance for $\mathrm{C}_{2} \mathrm{H}_{4}$ purification from $\mathrm{C}_{2} \mathrm{H}_{2}$ and $\mathrm{CO}_{2}$ impurities. In summary, there is much scope to further explore the separation properties and performance of switching CNs which already show, perhaps counterintuitively, great promise for several separations that have been a great challenge for rigid physisorbents.

Apart from working capacity and selectivity as discussed above, recyclability and kinetics are two other key metrics that must be evaluated for practical application, yet both remain largely understudied. Despite the strong recyclability demonstrated by Co(bdp) $)^{74}$ and X-pcu- $n$-Zn, ${ }^{\mathbf{1 4 6 , 1 4 7}}$ several 3D switching CNs, such as X-dia-1-Ni, ${ }^{67}$ DUT-8(Ni) ${ }^{246}$ and $\left[\mathrm{Zn}_{2}(\mathrm{DPT})_{2}(\mathrm{bpy})\right],{ }^{136}$ suffered from degradation in terms of switching pressure and uptake after multiple gas sorption cycles. In contrast, 2D layered switching CNs such as ELM-11 (ref. 246) and sql-1-Co-NCS ${ }^{\mathbf{1 4 4}}$ demonstrated excellent recyclability over at least 100 cycles. The strong recyclability performance of several 2D CNs might be attributed to the relatively low structural strain and/or weak inter-network interactions that accompany expansion/contraction during recycling. With respect to kinetics, the $\mathrm{CH}_{4}$ adsorption kinetics of ELM-11 reached saturation uptake in $10 \mathrm{~min}$ (ref. 59) and we demonstrated that the $\mathrm{CO}_{2}$ adsorption of sql-1-Co-NCS requires less than 30 min. ${ }^{144}$ In general, the adsorption kinetics of switching CNs is even less wellstudied than recyclability. 


\section{Conclusions}

We detail herein the scope of CNs that switch between closed and open phases, an emerging class of physisorbents, and discuss the impact of metal ions, linker ligands and adsorbates on switching parameters upon properties of relevance to gas storage and separations. We also address the mechanisms associated with switching between closed and open phases. Switching CNs offer potential advantages over rigid CNs which results from their extreme flexibility, the specific stimulus-response and unusual sorption properties. However, both scientific and practical hurdles remain to be overcome before there can be utility.

From a scientific perspective, the synthetic design principles for switching or, more generally, even soft CNs largely remain to be established. This is despite the relative maturity of crystal engineering with respect to design of CNs from first principles. The introduction of switching elements into CNs and realisation of structural dynamism remains somewhat unpredictable due to uncertainties over their self-assembly processes and the complex interplay of local and global flexibility. Indeed, as revealed by Table 5, other than the effect of temperature and pressure upon switching pressure, there is no obvious correlation between sorbates and switching pressure other than the general observation that polar sorbates tend to promote switching. Improvements in understanding and predictability of switching will come from in-depth investigation of the origin and mechanism of switching, which remains limited by a reliance on X-ray diffraction. ${ }^{247}$ It is therefore important to further exploit in situ characterization using techniques such as nuclear magnetic resonance, Raman spectroscopy, transmission electron microscopy and neutron scattering to broaden the scopes offered by diffraction experiments. ${ }^{45}$ In this context, given the dynamics of switching transformations, time-resolved in situ techniques are of particular importance. ${ }^{176,248}$ It is also worth mentioning that the performance of CNs is determined not only by their atomic level structure, but also by their macroscopic features, i.e., morphology, particle size, etc. Therefore, further insights into the roles of particle size, morphology, defects and disorder are needed. ${ }^{24-251}$ Finally, development of machine learning and task-specific theoretical modelling approaches merit increased attention since they might not only address the underlying mechanisms, but also offer predictable modelling of the performance of switching CNs with pre-defined functions. ${ }^{252-254}$

From a practical viewpoint, the hygroscopicity of CNs must be taken into account in addition to the aforementioned performance metrics (i.e., recyclability and kinetics). This is because hygroscopicity can strongly impact both the lifetime and the performance of switching CNs. ${ }^{255}$ In addition, that switching between closed and open phases usually results in large volume changes in switching CNs may pose challenges to downstream processes such as formulation/shaping. It should be noted that the activation can also influence the switching pressure and uptake. ${ }^{28,136}$ Cost of ingredients and processing is also a consideration that must be addressed when assessing the viability of CN-based products and technologies. Ironically, even though this is not considered by most academic researchers, this is perhaps the one factor that a chemist can control. With respect to processing, the use of mechanochemistry such as ball milling and twin-screw extrusion ${ }^{256}$ offers promise for scale-up and several well-known rigid CNs have been prepared 
with high efficiency using mechanochemistry. ${ }^{257}$ The suitability of mechanochemistry for synthesis of switching or soft CNs is even more understudied though.

In conclusion, we are perhaps approaching the "end of the beginning", but we are not yet there in terms of either design or properties. With respect to design, there are still just a few families of switching CNs and we remain mainly at the stage of empirical observation. With respect to properties, apart from adsorptive gas storage and mixture separation as discussed above, switching CNs and derived composites have been noted as having the potential to serve other emerging applications thanks to combination(s) of different applied stimuli such as light, redox and mechanical stress. ${ }^{258-261}$ Whereas these applications emphasise the relevance of switching CNs more than ever, there remains a large gap between a property serving as an indicator of performance and real-world applications. At this stage, ANG storage is perhaps the most promising short to medium term opportunity for end-use of switching CNs.

\section{Conflicts of interest}

There are no conflicts to declare.

\section{Acknowledgements}

M. J. Z. would like to acknowledge the support of Irish Research Council (IRCLA/ 2019/167) and Science Foundation Ireland (13/RP/B2549 and 16/IA/4624). S. M. thanks the Alexander von Humboldt Foundation for funding his postdoctoral research at TU Munich. S.-Q. W. would like to thank his colleague Dr Shaza Darwish for her proof reading and helpful suggestions.

\section{References}

1 S. R. Batten, N. R. Champness, X.-M. Chen, J. Garcia-Martinez, S. Kitagawa, L. Öhrström, M. O'Keeffe, M. P. Suh and J. Reedijk, Pure Appl. Chem., 2013, 85, 1715-1724.

2 L. R. MacGillivray, Metal-organic frameworks: design and application, Wiley, Hoboken, 2010.

3 D. Farrusseng, Metal-Organic Frameworks: Applications from Catalysis to Gas Storage, Wiley-VCH, Weinheim, 2011.

4 J. F. Keggin and F. D. Miles, Nature, 1936, 137, 577-578.

5 H. J. Buser, D. Schwarzenbach, W. Petter and A. Ludi, Inorg. Chem., 1977, 16, 2704-2710.

6 S. Mukherjee and M. J. Zaworotko, Trends Chem., 2020, 2, 506-518.

7 S. Kitagawa, R. Kitaura and S.-i. Noro, Angew. Chem., Int. Ed., 2004, 43, 23342375.

8 S. R. Batten, S. M. Neville and D. R. Turner, Coordination Polymers: Design, Analysis and Application, Royal Society of Chemistry, London, 2009.

9 J. J. Perry IV, J. A. Perman and M. J. Zaworotko, Chem. Soc. Rev., 2009, 38, 1400-1417.

10 T. R. Cook, Y.-R. Zheng and P. J. Stang, Chem. Rev., 2013, 113, 734-777.

11 B. Moulton and M. J. Zaworotko, Chem. Rev., 2001, 101, 1629-1658. 
12 O. M. Yaghi, M. O'Keeffe, N. W. Ockwig, H. K. Chae, M. Eddaoudi and J. Kim, Nature, 2003, 423, 705-714.

13 B. F. Hoskins and R. Robson, J. Am. Chem. Soc., 1989, 111, 5962-5964.

14 B. F. Hoskins and R. Robson, J. Am. Chem. Soc., 1990, 112, 1546-1554.

15 S. Ma and H.-C. Zhou, Chem. Commun., 2010, 46, 44-53.

16 J.-R. Li, J. Sculley and H.-C. Zhou, Chem. Rev., 2012, 112, 869-932.

17 P. A. Kobielska, A. J. Howarth, O. K. Farha and S. Nayak, Coord. Chem. Rev., 2018, 358, 92-107.

18 P. Horcajada, R. Gref, T. Baati, P. K. Allan, G. Maurin, P. Couvreur, G. Ferey, R. E. Morris and C. Serre, Chem. Rev., 2012, 112, 1232-1268.

19 J. Y. Lee, O. K. Farha, J. Roberts, K. A. Scheidt, S. B. T. Nguyen and J. T. Hupp, Chem. Soc. Rev., 2009, 38, 1450-1459.

20 P. Z. Moghadam, A. Li, X.-W. Liu, R. Bueno-Perez, S.-D. Wang, S. B. Wiggin, P. A. Wood and D. Fairen-Jimenez, Chem. Sci., 2020, 11, 8373-8387.

21 R. Taylor and P. A. Wood, Chem. Rev., 2019, 119, 9427-9477.

22 S. Kitagawa and M. Kondo, Bull. Chem. Soc. Jpn., 1998, 71, 1739-1753.

23 K. Uemura, R. Matsuda and S. Kitagawa, J. Solid State Chem., 2005, 178, 24202429.

24 S. Kitagawa and K. Uemura, Chem. Soc. Rev., 2005, 34, 109-119.

25 G. Alberti, S. Murcia-Mascaros and R. Vivani, J. Am. Chem. Soc., 1998, 120, 9291-9295.

26 G. Alberti, E. Brunet, C. Dionigi, O. Juanes, M. J. de la Mata, J. C. RodríguezUbis and R. Vivani, Angew. Chem., Int. Ed., 1999, 38, 3351-3353.

27 O.-S. Jung, Y. J. Kim, Y.-A. Lee, J. K. Park and H. K. Chae, J. Am. Chem. Soc., 2000, 122, 9921-9925.

28 D. Li and K. Kaneko, Chem. Phys. Lett., 2001, 335, 50-56.

29 A. J. Fletcher, E. J. Cussen, T. J. Prior, M. J. Rosseinsky, C. J. Kepert and K. M. Thomas, J. Am. Chem. Soc., 2001, 123, 10001-10011.

30 S. Horike, S. Shimomura and S. Kitagawa, Nat. Chem., 2009, 1, 695-704.

31 S. Krause, N. Hosono and S. Kitagawa, Angew. Chem., Int. Ed., 2020, 59, 1532515341.

32 S. Castellanos, F. Kapteijn and J. Gascon, CrystEngComm, 2016, 18, 40064012.

33 H.-L. Zhou, Y.-B. Zhang, J.-P. Zhang and X.-M. Chen, Nat. Commun., 2015, 6, 1-7.

34 I. Beurroies, M. Boulhout, P. L. Llewellyn, B. Kuchta, G. Férey, C. Serre and R. Denoyel, Angew. Chem., Int. Ed., 2010, 49, 7526-7529.

35 M.-H. Yu, B. Space, D. Franz, W. Zhou, C. He, L. Li, R. Krishna, Z. Chang, W. Li, T.-L. Hu and X.-H. Bu, J. Am. Chem. Soc., 2019, 141, 17703-17712.

36 H. Zeng, M. Xie, Y.-L. Huang, Y. Zhao, X.-J. Xie, J.-P. Bai, M.-Y. Wan, R. Krishna, W. Lu and D. Li, Angew. Chem., Int. Ed., 2019, 58, 8515-8519.

37 P. Zhao, H. Fang, S. Mukhopadhyay, A. Li, S. Rudic, I. J. McPherson, C. C. Tang, D. Fairen-Jimenez, S. C. E. Tsang and S. A. T. Redfern, Nat. Commun., 2019, 10, 1-8.

38 G. Férey and C. Serre, Chem. Soc. Rev., 2009, 38, 1380-1399.

39 A. J. Fletcher, K. M. Thomas and M. J. Rosseinsky, J. Solid State Chem., 2005, 178, 2491-2510.

40 C. R. Murdock, B. C. Hughes, Z. Lu and D. M. Jenkins, Coord. Chem. Rev., 2014, 258, 119-136. 
41 A. Schneemann, V. Bon, I. Schwedler, I. Senkovska, S. Kaskel and R. A. Fischer, Chem. Soc. Rev., 2014, 43, 6062-6096.

42 B. Qian, Z. Chang and X.-H. Bu, Top. Curr. Chem., 2020, 378, 5.

43 F. Bigdeli, C. T. Lollar, A. Morsali and H.-C. Zhou, Angew. Chem., Int. Ed., 2020, 59, 4652-4669.

44 S. B. Peh, A. Karmakar and D. Zhao, Trends Chem., 2020, 2, 199-213.

45 V. Bon, E. Brunner, A. Pöppl and S. Kaskel, Adv. Funct. Mater., 2020, 30, 1907847.

46 J.-P. Zhang, H.-L. Zhou, D.-D. Zhou, P.-Q. Liao and X.-M. Chen, Natl. Sci. Rev., 2018, 5, 907-919.

47 L. Vanduyfhuys, S. Rogge, J. Wieme, S. Vandenbrande, G. Maurin, M. Waroquier and V. Van Speybroeck, Nat. Commun., 2018, 9, 1-9.

48 Z. Chang, D.-H. Yang, J. Xu, T.-L. Hu and X.-H. Bu, Adv. Mater., 2015, 27, 54325441.

49 S. K. Elsaidi, M. H. Mohamed, D. Banerjee and P. K. Thallapally, Coord. Chem. Rev., 2018, 358, 125-152.

50 J. H. Lee, S. Jeoung, Y. G. Chung and H. R. Moon, Coord. Chem. Rev., 2019, 389, 161-188.

51 K. Seki, Phys. Chem. Chem. Phys., 2002, 4, 1968-1971.

52 K. Biradha and M. Fujita, Angew. Chem., Int. Ed., 2002, 41, 3392-3395.

53 J.-S. Qin, S. Yuan, A. Alsalme and H.-C. Zhou, ACS Appl. Mater. Interfaces, 2017, 9, 33408-33412.

54 Q.-f. Qiu, C.-X. Chen, Z.-W. Wei, C.-C. Cao, N.-X. Zhu, H.-P. Wang, D. Wang, J.-J. Jiang and C.-Y. Su, Inorg. Chem., 2019, 58, 61-64.

55 C. Serre, F. Millange, C. Thouvenot, M. Nogues, G. Marsolier, D. Louër and G. Férey, J. Am. Chem. Soc., 2002, 124, 13519-13526.

56 C. Mellot-Draznieks, C. Serre, S. Surblé, N. Audebrand and G. Férey, J. Am. Chem. Soc., 2005, 127, 16273-16278.

57 C. Serre, C. Mellot-Draznieks, S. Surblé, N. Audebrand, Y. Filinchuk and G. Férey, Science, 2007, 315, 1828-1831.

58 A. U. Ortiz, A. Boutin, A. H. Fuchs and F.-X. Coudert, Phys. Rev. Lett., 2012, 109, 195502.

59 H. Kanoh, A. Kondo, H. Noguchi, H. Kajiro, A. Tohdoh, Y. Hattori, W.-C. Xu, M. Inoue, T. Sugiura, K. Morita, H. Tanaka, T. Ohba and K. Kaneko, J. Colloid Interface Sci., 2009, 334, 1-7.

60 K. Yang, G. Zhou and Q. Xu, RSC Adv., 2016, 6, 37506-37514.

61 H. Deng, M. A. Olson, J. F. Stoddart and O. M. Yaghi, Nat. Chem., 2010, 2, 439443.

62 A. Gonzalez-Nelson, F.-X. Coudert and M. A. van der Veen, Nanomaterials, 2019, 9, 330.

63 S. Krause, V. Bon, U. Stoeck, I. Senkovska, D. M. Toebbens, D. Wallacher and S. Kaskel, Angew. Chem., Int. Ed., 2017, 56, 10676-10680.

64 P. Kanoo, R. Haldar, S. K. Reddy, A. Hazra, S. Bonakala, R. Matsuda, S. Kitagawa, S. Balasubramanian and T. K. Maji, Chem.-Eur. J., 2016, 22, 15864-15873.

65 R. Kitaura, K. Seki, G. Akiyama and S. Kitagawa, Angew. Chem., Int. Ed., 2003, 42, 428-431.

66 D. Tanaka, K. Nakagawa, M. Higuchi, S. Horike, Y. Kubota, T. C. Kobayashi, M. Takata and S. Kitagawa, Angew. Chem., Int. Ed., 2008, 47, 3914-3918. 
67 Q. Y. Yang, P. Lama, S. Sen, M. Lusi, K. J. Chen, W. Y. Gao, M. Shivanna, T. Pham, N. Hosono, S. Kusaka, J. J. Perry IV, S. Ma, B. Space, L. J. Barbour, S. Kitagawa and M. J. Zaworotko, Angew. Chem., Int. Ed., 2018, 57, 5684-5689. 68 M. Thommes, K. Kaneko, A. V. Neimark, J. P. Olivier, F. Rodriguez-Reinoso, J. Rouquerol and K. S. Sing, Pure Appl. Chem., 2015, 87, 1051-1069.

69 S. Bourrelly, P. L. Llewellyn, C. Serre, F. Millange, T. Loiseau and G. Férey, J. Am. Chem. Soc., 2005, 127, 13519-13521.

70 A. Kondo, H. Noguchi, L. Carlucci, D. M. Proserpio, G. Ciani, H. Kajiro, T. Ohba, H. Kanoh and K. Kaneko, J. Am. Chem. Soc., 2007, 129, 12362-12363.

71 A. Schneemann, P. Vervoorts, I. Hante, M. Tu, S. Wannapaiboon, C. Sternemann, M. Paulus, D. C. F. Wieland, S. Henke and R. A. Fischer, Chem. Mater., 2018, 30, 1667-1676.

72 S.-Q. Wang, X.-Q. Meng, M. Vandichel, S. Darwish, Z. Chang, X.-H. Bu and M. J. Zaworotko, ACS Appl. Mater. Interfaces, 2021, 13, 23877-23883.

73 M. Shivanna, Q.-Y. Yang, A. Bajpai, S. Sen, N. Hosono, S. Kusaka, T. Pham, K. A. Forrest, B. Space, S. Kitagawa and M. J. Zaworotko, Sci. Adv., 2018, 4, eaaq1636.

74 J. A. Mason, J. Oktawiec, M. K. Taylor, M. R. Hudson, J. Rodriguez, J. E. Bachman, M. I. Gonzalez, A. Cervellino, A. Guagliardi, C. M. Brown, P. L. Llewellyn, N. Masciocchi and J. R. Long, Nature, 2015, 527, 357-361.

75 E. Coronado and G. Minguez Espallargas, Chem. Soc. Rev., 2013, 42, 15251539.

76 S. Castellanos, F. Kapteijn and J. Gascon, CrystEngComm, 2016, 18, 40064012.

77 O. Drath and C. Boskovic, Coord. Chem. Rev., 2018, 375, 256-266.

78 W. D. Schaeffer, W. S. Dorsey, D. A. Skinner and C. G. Christian, J. Am. Chem. Soc., 1957, 79, 5870-5876.

79 S. A. Allison and R. M. Barrer, J. Chem. Soc. A, 1969, 1717-1723.

80 T. Dewa, K. Endo and Y. Aoyama, J. Am. Chem. Soc., 1998, 120, 8933-8940.

81 Z. Wang, N. Sikdar, S.-Q. Wang, X. Li, M. Yu, X.-H. Bu, Z. Chang, X. Zou, Y. Chen, P. Cheng, K. Yu, M. J. Zaworotko and Z. Zhang, J. Am. Chem. Soc., 2019, 141, 9408-9414.

82 N. Sun, S.-Q. Wang, R. Zou, W.-G. Cui, A. Zhang, T. Zhang, Q. Li, Z.-Z. Zhuang, Y.-H. Zhang, J. Xu, M. J. Zaworotko and X.-H. Bu, Chem. Sci., 2019, 10, 88508854.

83 A. M. Kałuża, S. Mukherjee, S.-Q. Wang, D. J. O'Hearn and M. J. Zaworotko, Chem. Commun., 2020, 56, 1940-1943.

84 G. B. Gardner, D. Venkataraman, J. S. Moore and S. Lee, Nature, 1995, 374, 792-795.

85 L. Li, R. Krishna, Y. Wang, X. Wang, J. Yang and J. Li, Eur. J. Inorg. Chem., 2016, 2016, 4457-4462.

86 M. Ichikawa, A. Kondo, H. Noguchi, N. Kojima, T. Ohba, H. Kajiro, Y. Hattori and H. Kanoh, Langmuir, 2016, 32, 9722-9726.

87 S. Hiraide, H. Tanaka, N. Ishikawa and M. T. Miyahara, ACS Appl. Mater. Interfaces, 2017, 9, 41066-41077.

88 A. Kondo, H. Noguchi, S. Ohnishi, H. Kajiro, A. Tohdoh, Y. Hattori, W.-C. Xu, H. Tanaka, H. Kanoh and K. Kaneko, Nano Lett., 2006, 6, 2581-2584.

89 H. Kajiro, A. Kondo, K. Kaneko and H. Kanoh, Int. J. Mol. Sci., 2010, 11, 38033845. 
90 V. Bon, I. Senkovska, D. Wallacher, A. Heerwig, N. Klein, I. Zizak, R. Feyerherm, E. Dudzik and S. Kaskel, Microporous Mesoporous Mater., 2014, 188, 190-195.

91 K. Uemura, S. Kitagawa, M. Kondo, K. Fukui, R. Kitaura, H.-C. Chang and T. Mizutani, Chem.-Eur. J., 2002, 8, 3586-3600.

92 R. Kitaura, K. Fujimoto, S. i. Noro, M. Kondo and S. Kitagawa, Angew. Chem., Int. Ed., 2002, 41, 133-135.

93 Y. Sakata, S. Furukawa, M. Kondo, K. Hirai, N. Horike, Y. Takashima, H. Uehara, N. Louvain, M. Meilikhov, T. Tsuruoka, S. Isoda, W. Kosaka, O. Sakata and S. Kitagawa, Science, 2013, 339, 193-196.

94 Y. Inubushi, S. Horike, T. Fukushima, G. Akiyama, R. Matsuda and S. Kitagawa, Chem. Commun., 2010, 46, 9229-9231.

95 K. Uemura, S. Kitagawa, K. Fukui and K. Saito, J. Am. Chem. Soc., 2004, 126, 3817-3828.

96 T. K. Maji, G. Mostafa, R. Matsuda and S. Kitagawa, J. Am. Chem. Soc., 2005, 127, 17152-17153.

97 B. Chen, C. Liang, J. Yang, D. S. Contreras, Y. L. Clancy, E. B. Lobkovsky, O. M. Yaghi and S. Dai, Angew. Chem., Int. Ed., 2006, 45, 1390-1393.

98 S. Xiang, W. Zhou, J. M. Gallegos, Y. Liu and B. Chen, J. Am. Chem. Soc., 2009, 131, 12415-12419.

99 P. M. Bhatt, E. Batisai, V. J. Smith and L. J. Barbour, Chem. Commun., 2016, 52, 11374-11377.

100 S. Shimomura, S. Horike, R. Matsuda and S. Kitagawa, J. Am. Chem. Soc., 2007, 129, 10990-10991.

101 H. J. Choi, M. Dincă and J. R. Long, J. Am. Chem. Soc., 2008, 130, 7848-7850.

102 F. Salles, G. Maurin, C. Serre, P. L. Llewellyn, C. Knofel, H. J. Choi, Y. Filinchuk, L. Oliviero, A. Vimont, J. R. Long and G. Ferey, J. Am. Chem. Soc., 2010, 132, 13782-13788.

103 M. K. Taylor, T. Runčevski, J. Oktawiec, J. E. Bachman, R. L. Siegelman, H. Jiang, J. A. Mason, J. D. Tarver and J. R. Long, J. Am. Chem. Soc., 2018, 140, 10324-10331.

104 A. Kondo, A. Chinen, H. Kajiro, T. Nakagawa, K. Kato, M. Takata, Y. Hattori, F. Okino, T. Ohba, K. Kaneko and H. Kanoh, Chem.-Eur. J., 2009, 15, 75497553.

105 H. S. Choi and M. P. Suh, Angew. Chem., Int. Ed., 2009, 48, 6865-6869.

106 P. L. Llewellyn, P. Horcajada, G. Maurin, T. Devic, N. Rosenbach, S. Bourrelly, C. Serre, D. Vincent, S. Loera-Serna, Y. Filinchuk and G. Ferey, J. Am. Chem. Soc., 2009, 131, 13002-13008.

107 N. Guillou, S. Bourrelly, P. L. Llewellyn, R. I. Walton and F. Millange, CrystEngComm, 2015, 17, 422-429.

108 M. Agrawal, S. Bhattacharyya, Y. Huang, K. C. Jayachandrababu, C. R. Murdock, J. A. Bentley, A. Rivas-Cardona, M. M. Mertens, K. S. Walton, D. S. Sholl and S. Nair, J. Phys. Chem. C, 2018, 122, 386-397.

109 J. Seo, R. Matsuda, H. Sakamoto, C. Bonneau and S. Kitagawa, J. Am. Chem. Soc., 2009, 131, 12792-12800.

110 H. Chun and J. Seo, Inorg. Chem., 2009, 48, 9980-9982.

111 J. Rabone, Y. F. Yue, S. Y. Chong, K. C. Stylianou, J. Bacsa, D. Bradshaw, G. R. Darling, N. G. Berry, Y. Z. Khimyak, A. Y. Ganin, P. Wiper, J. B. Claridge and M. J. Rosseinsky, Science, 2010, 329, 1053-1057. 
112 T. Fukushima, S. Horike, Y. Inubushi, K. Nakagawa, Y. Kubota, M. Takata and S. Kitagawa, Angew. Chem., Int. Ed., 2010, 49, 4820-4824.

113 N. Klein, C. Herzog, M. Sabo, I. Senkovska, J. Getzschmann, S. Paasch, M. R. Lohe, E. Brunner and S. Kaskel, Phys. Chem. Chem. Phys., 2010, 12, 11778-11784.

114 N. Klein, H. C. Hoffmann, A. Cadiau, J. Getzschmann, M. R. Lohe, S. Paasch, T. Heydenreich, K. Adil, I. Senkovska, E. Brunner and S. Kaskel, J. Mater. Chem., 2012, 22, 10303-10312.

115 V. Bon, N. Klein, I. Senkovska, A. Heerwig, J. Getzschmann, D. Wallacher, I. Zizak, M. Brzhezinskaya, U. Mueller and S. Kaskel, Phys. Chem. Chem. Phys., 2015, 17, 17471-17479.

116 N. Kavoosi, T. Savchenko, I. Senkovska, M. Maliuta, V. Bon, A. Eychmüller and S. Kaskel, Microporous Mesoporous Mater., 2018, 271, 169-174.

117 S. Ehrling, I. Senkovska, V. Bon, J. D. Evans, P. Petkov, Y. Krupskaya, V. Kataev, T. Wulf, A. Krylov, A. Vtyurin, S. Krylova, S. Adichtchev, E. Slyusareva, M. S. Weiss, B. Büchner, T. Heine and S. Kaskel, J. Mater. Chem. A, 2019, 7, 21459-21475.

118 H. Wu, R. S. Reali, D. A. Smith, M. C. Trachtenberg and J. Li, Chem.-Eur. J., 2010, 16, 13951-13954.

119 N. Nijem, H. Wu, P. Canepa, A. Marti, K. J. Balkus, T. Thonhauser, J. Li and Y. J. Chabal, J. Am. Chem. Soc., 2012, 134, 15201-15204.

120 J. Seo, C. Bonneau, R. Matsuda, M. Takata and S. Kitagawa, J. Am. Chem. Soc., 2011, 133, 9005-9013.

121 S. Henke, A. Schneemann, A. Wuetscher and R. A. Fischer, J. Am. Chem. Soc., 2012, 134, 9464-9474.

122 J. P. Mowat, V. R. Seymour, J. M. Griffin, S. P. Thompson, A. M. Slawin, D. Fairen-Jimenez, T. Düren, S. E. Ashbrook and P. A. Wright, Dalton Trans., 2012, 41, 3937-3941.

123 L. Chen, J. P. S. Mowat, D. Fairen-Jimenez, C. A. Morrison, S. P. Thompson, P. A. Wright and T. Duren, J. Am. Chem. Soc., 2013, 135, 15763-15773.

124 X.-M. Liu, R.-B. Lin, J.-P. Zhang and X.-M. Chen, Inorg. Chem., 2012, 51, 56865692.

125 K. Fukuhara, S.-i. Noro, K. Sugimoto, T. Akutagawa, K. Kubo and T. Nakamura, Inorg. Chem., 2013, 52, 4229-4237.

126 B. Joarder, S. Mukherjee, A. K. Chaudhari, A. V. Desai, B. Manna and S. K. Ghosh, Chem.-Eur. J., 2014, 20, 15303-15308.

127 S. Mukherjee, B. Joarder, B. Manna, A. V. Desai, A. K. Chaudhari and S. K. Ghosh, Sci. Rep., 2014, 4, 5761.

128 S. Mukherjee, B. Joarder, A. V. Desai, B. Manna, R. Krishna and S. K. Ghosh, Inorg. Chem., 2015, 54, 4403-4408.

129 J. Wang, J. Luo, J. Zhao, D.-S. Li, G. Li, Q. Huo and Y. Liu, Cryst. Growth Des., 2014, 14, 2375-2380.

130 M. Handke, H. Weber, M. Lange, J. Moellmer, J. Lincke, R. Glaeser, R. Staudt and H. Krautscheid, Inorg. Chem., 2014, 53, 7599-7607.

131 C. Wang, L. Li, J. G. Bell, X. Lv, S. Tang, X. Zhao and K. M. Thomas, Chem. Mater., 2015, 27, 1502-1516.

132 P. Kanoo, R. Haldar, S. K. Reddy, A. Hazra, S. Bonakala, R. Matsuda, S. Kitagawa, S. Balasubramanian and T. K. Maji, Chem.-Eur. J., 2016, 22, 15864-15873. 
133 M. K. Taylor, T. Runčevski, J. Oktawiec, M. I. Gonzalez, R. L. Siegelman, J. A. Mason, J. Ye, C. M. Brown and J. R. Long, J. Am. Chem. Soc., 2016, 138, 15019-15026.

134 D. Banerjee, H. Wang, A. M. Plonka, T. J. Emge, J. B. Parise and J. Li, Chem.Eur. J., 2016, 22, 11816-11825.

135 X. Sun, S. Yao, G. Li, L. Zhang, Q. Huo and Y. Liu, Inorg. Chem., 2017, 56, 6645-6651.

136 E. R. Engel, A. Jouaiti, C. X. Bezuidenhout, M. W. Hosseini and L. J. Barbour, Angew. Chem., 2017, 129, 9000-9004.

137 P. Lama and L. J. Barbour, J. Am. Chem. Soc., 2018, 140, 2145-2150.

138 S. Sen, N. Hosono, J.-J. Zheng, S. Kusaka, R. Matsuda, S. Sakaki and S. Kitagawa, J. Am. Chem. Soc., 2017, 139, 18313-18321.

139 S. Krause, V. Bon, U. Stoeck, I. Senkovska, D. M. Toebbens, D. Wallacher and S. Kaskel, Angew. Chem., Int. Ed., 2017, 56, 10676-10680.

140 S. Krause, V. Bon, H. Du, R. E. Dunin-Borkowski, U. Stoeck, I. Senkovska and S. Kaskel, Beilstein J. Nanotechnol., 2019, 10, 1737-1744.

141 J. Jin, X. Zhao, P. Feng and X. Bu, Angew. Chem., Int. Ed., 2018, 57, 3737-3741.

142 H. Yang, F. Guo, P. Lama, W.-Y. Gao, H. Wu, L. J. Barbour, W. Zhou, J. Zhang, B. Aguila and S. Ma, ACS Cent. Sci., 2018, 4, 1194-1200.

143 Y.-X. Shi, W.-X. Li, W.-H. Zhang and J.-P. Lang, Inorg. Chem., 2018, 57, 86278633.

144 S.-Q. Wang, Q.-Y. Yang, S. Mukherjee, D. O’Nolan, E. Patyk-Kazmierczak, K.-J. Chen, M. Shivanna, C. Murray, C. C. Tang and M. J. Zaworotko, Chem. Commun., 2018, 54, 7042-7045.

145 S.-Q. Wang, S. Mukherjee, E. Patyk-Kaźmierczak, S. Darwish, A. Bajpai, Q.-Y. Yang and M. J. Zaworotko, Angew. Chem., Int. Ed., 2019, 58, 6630-6634.

146 A.-X. Zhu, Q.-Y. Yang, A. Kumar, C. Crowley, S. Mukherjee, K.-J. Chen, S.-Q. Wang, D. O'Nolan, M. Shivanna and M. J. Zaworotko, J. Am. Chem. Soc., 2018, 140, 15572-15576.

147 A.-X. Zhu, Q.-Y. Yang, S. Mukherjee, A. Kumar, C.-H. Deng, A. A. Bezrukov, M. Shivanna and M. J. Zaworotko, Angew. Chem., Int. Ed., 2019, 58, 1821218217.

148 X. Wang, R. Krishna, L. Li, B. Wang, T. He, Y.-Z. Zhang, J.-R. Li and J. Li, Chem. Eng. J., 2018, 346, 489-496.

149 A. Hazra, D. P. van Heerden, S. Sanyal, P. Lama, C. Esterhuysen and L. J. Barbour, Chem. Sci., 2019, 10, 10018-10024.

150 S. Millan, B. Gil-Hernandez, E. Milles, S. Gokpinar, G. Makhloufi, A. Schmitz, C. Schlusener and C. Janiak, Dalton Trans., 2019, 48, 8057-8067.

151 B.-Q. Song, Q.-Y. Yang, S.-Q. Wang, M. Vandichel, A. Kumar, C. Crowley, N. Kumar, C.-H. Deng, V. Gascon Perez, M. Lusi, H. Wu, W. Zhou and M. J. Zaworotko, J. Am. Chem. Soc., 2020, 142, 6896-6901.

152 Q. Dong, X. Zhang, S. Liu, R. B. Lin, Y. Guo, Y. Ma, A. Yonezu, R. Krishna, G. Liu, J. Duan, R. Matsuda, W. Jin and B. Chen, Angew. Chem., Int. Ed., 2020, 59, 22756-22762.

153 A. Kondo, H. Kajiro, T. Nakagawa, H. Tanaka and H. Kanoh, Dalton Trans., 2020, 49, 3692-3699.

154 K. Roztocki, F. Formalik, A. Krawczuk, I. Senkovska, B. Kuchta, S. Kaskel and D. Matoga, Angew. Chem., Int. Ed., 2020, 59, 4491-4497.

155 F. Millange and R. I. Walton, Isr. J. Chem., 2018, 58, 1019-1035. 
156 F. Millange, C. Serre and G. Ferey, Chem. Commun., 2002, 822-823.

157 G. Ferey, M. Latroche, C. Serre, F. Millange, T. Loiseau and A. PercheronGuegan, Chem. Commun., 2003, 2976-2977.

158 T. R. Whitfield, X. Wang, L. Liu and A. J. Jacobson, Solid State Sci., 2005, 7, 1096-1103.

159 E. V. Anokhina, M. Vougo-Zanda, X. Wang and A. J. Jacobson, J. Am. Chem. Soc., 2005, 127, 15000-15001.

160 M. Vougo-Zanda, J. Huang, E. Anokhina, X. Wang and A. J. Jacobson, Inorg. Chem., 2008, 47, 11535-11542.

161 J. P. S. Mowat, S. R. Miller, A. M. Z. Slawin, V. R. Seymour, S. E. Ashbrook and P. A. Wright, Microporous Mesoporous Mater., 2011, 142, 322-333.

162 N. L. Rosi, J. Kim, M. Eddaoudi, B. Chen, M. O’Keeffe and O. M. Yaghi, J. Am. Chem. Soc., 2005, 127, 1504-1518.

163 A. Schoedel, M. Li, D. Li, M. O'Keeffe and O. M. Yaghi, Chem. Rev., 2016, 116, 12466-12535.

164 D. J. O’Hearn, A. Bajpai and M. J. Zaworotko, Small, 2021, 17, 2006351.

165 C. Serre, F. Millange, C. Thouvenot, M. Nogues, G. Marsolier, D. Louër and G. Férey, J. Am. Chem. Soc., 2002, 124, 13519-13526.

166 T. Loiseau, C. Serre, C. Huguenard, G. Fink, F. Taulelle, M. Henry, T. Bataille and G. Férey, Chem.-Eur. J., 2004, 10, 1373-1382.

167 N. Guillou, F. Millange and R. I. Walton, Chem. Commun., 2011, 47, 713-715.

168 C. Serre, S. Bourrelly, A. Vimont, N. A. Ramsahye, G. Maurin, P. L. Llewellyn, M. Daturi, Y. Filinchuk, O. Leynaud, P. Barnes and G. Ferey, Adv. Mater., 2007, 19, 2246-2251.

169 S. Bourrelly, B. Moulin, A. Rivera, G. Maurin, S. Devautour-Vinot, C. Serre, T. Devic, P. Horcajada, A. Vimont, G. Clet, M. Daturi, J.-C. Lavalley, S. Loera-Serna, R. Denoyel, P. L. Llewellyn and G. Ferey, J. Am. Chem. Soc., 2010, 132, 9488-9498.

170 T. K. Trung, P. Trens, N. Tanchoux, S. Bourrelly, P. L. Llewellyn, S. LoeraSerna, C. Serre, T. Loiseau, F. Fajula and G. Ferey, J. Am. Chem. Soc., 2008, 130, 16926-16932.

171 V. Finsy, C. E. A. Kirschhock, G. Vedts, M. Maes, L. Alaerts, D. E. De Vos, G. V. Baron and J. F. M. Denayer, Chem.-Eur. J., 2009, 15, 7724-7731.

172 F. Millange, N. Guillou, R. I. Walton, J.-M. Greneche, I. Margiolaki and G. Ferey, Chem. Commun., 2008, 4732-4734.

173 F. Millange, C. Serre, N. Guillou, G. Ferey and R. I. Walton, Angew. Chem., Int. Ed., 2008, 47, 4100-4105.

174 P. Horcajada, C. Serre, G. Maurin, N. A. Ramsahye, F. Balas, M. Vallet-Regi, M. Sebban, F. Taulelle and G. Ferey, J. Am. Chem. Soc., 2008, 130, 6774-6780.

175 F. Millange, N. Guillou, M. E. Medina, G. Ferey, A. Carlin-Sinclair, K. M. Golden and R. I. Walton, Chem. Mater., 2010, 22, 4237-4245.

176 R. I. Walton, A. S. Munn, N. Guillou and F. Millange, Chem.-Eur. J., 2011, 17, 7069-7079.

177 R. El Osta, A. Carlin-Sinclair, N. Guillou, R. I. Walton, F. Vermoortele, M. Maes, D. de Vos and F. Millange, Chem. Mater., 2012, 24, 2781-2791.

178 B. Van de Voorde, A. S. Munn, N. Guillou, F. Millange, D. E. De Vos and R. I. Walton, Phys. Chem. Chem. Phys., 2013, 15, 8606-8615.

179 M. Sanselme, J.-M. Grenèche, M. Riou-Cavellec and G. Férey, Solid State Sci., 2004, 6, 853-858. 
180 S. Bauer, C. Serre, T. Devic, P. Horcajada, J. Marrot, G. Férey and N. Stock, Inorg. Chem., 2008, 47, 7568-7576.

181 T. Devic, P. Horcajada, C. Serre, F. Salles, G. Maurin, B. Moulin, D. Heurtaux, G. Clet, A. Vimont, J.-M. Greneche, B. Le Ouay, F. Moreau, E. Magnier, Y. Filinchuk, J. Marrot, J.-C. Lavalley, M. Daturi and G. Ferey, J. Am. Chem. Soc., 2010, 132, 1127-1136.

182 N. A. Ramsahye, T.-K. Trung, S. Bourrelly, Q.-Y. Yang, T. Devic, G. Maurin, P. Horcajada, P. L. Llewellyn, P. Yot, C. Serre, Y. Filinchuk, F. Fajula, G. Ferey and P. Trens, J. Phys. Chem. C, 2011, 115, 18683-18695.

183 T. Devic, F. Salles, S. Bourrelly, B. Moulin, G. Maurin, P. Horcajada, C. Serre, A. Vimont, J.-C. Lavalley, H. Leclerc, G. Clet, M. Daturi, P. L. Llewellyn, Y. Filinchuk and G. Ferey, J. Mater. Chem., 2012, 22, 10266-10273.

184 K. Seki and W. Mori, J. Phys. Chem. B, 2002, 106, 1380-1385.

185 R. Kitaura, F. Iwahori, R. Matsuda, S. Kitagawa, Y. Kubota, M. Takata and T. C. Kobayashi, Inorg. Chem., 2004, 43, 6522-6524.

186 H. Chun, D. N. Dybtsev, H. Kim and K. Kim, Chem.-Eur. J., 2005, 11, 35213529.

187 D. Tanaka, M. Higuchi, S. Horike, R. Matsuda, Y. Kinoshita, N. Yanai and S. Kitagawa, Chem.-Asian J., 2008, 3, 1343-1349.

188 F. ZareKarizi, M. Joharian and A. Morsali, J. Mater. Chem. A, 2018, 6, 1928819329.

189 D. N. Dybtsev, H. Chun and K. Kim, Angew. Chem., Int. Ed., 2004, 43, 50335036.

190 K. Uemura, Y. Yamasaki, Y. Komagawa, K. Tanaka and H. Kita, Angew. Chem., Int. Ed., 2007, 46, 6662-6665.

191 K. Uemura, Y. Yamasaki, F. Onishi, H. Kita and M. Ebihara, Inorg. Chem., 2010, 49, 10133-10143.

192 J. S. Grosch and F. Paesani, J. Am. Chem. Soc., 2012, 134, 4207-4215.

193 J. Y. Lee, L. Pan, X. Huang, T. J. Emge and J. Li, Adv. Funct. Mater., 2011, 21, 993-998.

194 H. Miura, V. Bon, I. Senkovska, S. Ehrling, S. Watanabe, M. Ohba and S. Kaskel, Dalton Trans., 2017, 46, 14002-14011.

195 M. Shivanna, Q.-Y. Yang, A. Bajpai, E. Patyk-Kazmierczak and M. J. Zaworotko, Nat. Commun., 2018, 9, 3080.

196 P. Nugent, Y. Belmabkhout, S. D. Burd, A. J. Cairns, R. Luebke, K. Forrest, T. Pham, S. Q. Ma, B. Space, L. Wojtas, M. Eddaoudi and M. J. Zaworotko, Nature, 2013, 495, 80-84.

197 X. L. Cui, K. J. Chen, H. B. Xing, Q. W. Yang, R. Krishna, Z. B. Bao, H. Wu, W. Zhou, X. L. Dong, Y. Han, B. Li, Q. L. Ren, M. J. Zaworotko and B. L. Chen, Science, 2016, 353, 141-144.

198 S. K. Elsaidi, M. H. Mohamed, C. M. Simon, E. Braun, T. Pham, K. A. Forrest, W. Xu, D. Banerjee, B. Space, M. J. Zaworotko and P. K. Thallapally, Chem. Sci., 2017, 8, 2373-2380.

199 L. Yang, X. Cui, Y. Zhang, Q. Yang and H. Xing, J. Mater. Chem. A, 2018, 6, 24452-24458.

200 L. Carlucci, G. Ciani, D. M. Proserpio and A. Sironi, J. Chem. Soc., Chem. Commun., 1994, 2755-2756.

201 M. J. Zaworotko, Chem. Soc. Rev., 1994, 23, 283-288. 
202 S. K. Elsaidi, M. H. Mohamed, L. Wojtas, A. Chanthapally, T. Pham, B. Space, J. J. Vittal and M. J. Zaworotko, J. Am. Chem. Soc., 2014, 136, 5072-5077.

203 E. J. Carrington, C. A. McAnally, A. J. Fletcher, S. P. Thompson, M. Warren and L. Brammer, Nat. Chem., 2017, 9, 882-889.

204 S. Galli, N. Masciocchi, V. Colombo, A. Maspero, G. Palmisano, F. J. LópezGarzón, M. Domingo-García, I. Fernández-Morales, E. Barea and J. A. R. Navarro, Chem. Mater., 2010, 22, 1664-1672.

205 T. G. Mitina and V. A. Blatov, Cryst. Growth Des., 2013, 13, 1655-1664.

206 M. J. Zaworotko, Chem. Commun., 2001, 1-9.

207 M. Fujita, Y. J. Kwon, S. Washizu and K. Ogura, J. Am. Chem. Soc., 1994, 116, 1151-1152.

208 J. Lu, T. Paliwala, S. C. Lim, C. Yu, T. Niu and A. J. Jacobson, Inorg. Chem., 1997, 36, 923-929.

209 K. Biradha, A. Mondal, B. Moulton and M. J. Zaworotko, J. Chem. Soc., Dalton Trans., 2000, 3837-3844.

210 J. vanden Bergh, C. Gücüyener, E. A. Pidko, E. J. M. Hensen, J. Gascon and F. Kapteijn, Chem.-Eur. J., 2011, 17, 8832-8840.

211 D. Fairen-Jimenez, S. A. Moggach, M. T. Wharmby, P. A. Wright, S. Parsons and T. Düren, J. Am. Chem. Soc., 2011, 133, 8900-8902.

212 N. Lock, Y. Wu, M. Christensen, L. J. Cameron, V. K. Peterson, A. J. Bridgeman, C. J. Kepert and B. B. Iversen, J. Phys. Chem. C, 2010, 114, 16181-16186.

213 L. Sarkisov, R. L. Martin, M. Haranczyk and B. Smit, J. Am. Chem. Soc., 2014, 136, 2228-2231.

214 S. Bourrelly, P. L. Llewellyn, C. Serre, F. Millange, T. Loiseau and G. Férey, J. Am. Chem. Soc., 2005, 127, 13519-13521.

215 N. Rosenbach Jr, A. Ghoufi, I. Deroche, P. L. Llewellyn, T. Devic, S. Bourrelly, C. Serre, G. Ferey and G. Maurin, Phys. Chem. Chem. Phys., 2010, 12, 64286437.

216 R. Demuynck, S. M. J. Rogge, L. Vanduyfhuys, J. Wieme, M. Waroquier and V. Van Speybroeck, J. Chem. Theory Comput., 2017, 13, 5861-5873.

217 R. Numaguchi, H. Tanaka, S. Watanabe and M. T. Miyahara, J. Chem. Phys., 2013, 138, 054708.

218 M. Pera-Titus and D. Farrusseng, J. Phys. Chem. C, 2012, 116, 1638-1649.

219 A. Gonzalez-Nelson, F.-X. Coudert and M. A. van der Veen, Nanomaterials, 2019, 9, 330.

220 M. P. Suh, H. J. Park, T. K. Prasad and D.-W. Lim, Chem. Rev., 2012, 112, 782835.

221 L. J. Murray, M. Dinca and J. R. Long, Chem. Soc. Rev., 2009, 38, 1294-1314.

222 B. Li, H.-M. Wen, W. Zhou, J. Q. Xu and B. Chen, Chem, 2016, 1, 557-580.

223 K. Sumida, D. L. Rogow, J. A. Mason, T. M. McDonald, E. D. Bloch, Z. R. Herm, T.-H. Bae and J. R. Long, Chem. Rev., 2012, 112, 724-781.

224 S. Kitagawa, Angew. Chem., Int. Ed., 2015, 54, 10686-10687.

225 M. Bonneau, C. Lavenn, K. Sugimoto, A. Legrand, T. Ogawa, F.-X. Coudert, R. Réau, K.-i. Otake and S. Kitagawa, Research Square, 2020, DOI: 10.21203/ rs.3.rs-102861/v1.

226 Y. Peng, V. Krungleviciute, I. Eryazici, J. T. Hupp, O. K. Farha and T. Yildirim, J. Am. Chem. Soc., 2013, 135, 11887-11894. 
227 F. Gándara, H. Furukawa, S. Lee and O. M. Yaghi, J. Am. Chem. Soc., 2014, 136, 5271-5274.

228 B. Li, H.-M. Wen, H. Wang, H. Wu, M. Tyagi, T. Yildirim, W. Zhou and B. Chen, J. Am. Chem. Soc., 2014, 136, 6207-6210.

229 J. A. Mason, M. Veenstra and J. R. Long, Chem. Sci., 2014, 5, 32-51.

230 D. Alezi, Y. Belmabkhout, M. Suyetin, P. M. Bhatt, Ł. J. Weseliński, V. Solovyeva, K. Adil, I. Spanopoulos, P. N. Trikalitis and A.-H. Emwas, J. Am. Chem. Soc., 2015, 137, 13308-13318.

231 J. M. Lin, C. T. He, Y. Liu, P. Q. Liao, D. D. Zhou, J. P. Zhang and X. M. Chen, Angew. Chem., Int. Ed., 2016, 55, 4674-4678.

232 I. Spanopoulos, C. Tsangarakis, E. Klontzas, E. Tylianakis, G. Froudakis, K. Adil, Y. Belmabkhout, M. Eddaoudi and P. N. Trikalitis, J. Am. Chem. Soc., 2016, 138, 1568-1574.

233 Z. Chen, P. Li, R. Anderson, X. Wang, X. Zhang, L. Robison, L. R. Redfern, S. Moribe, T. Islamoglu, D. A. Gómez-Gualdrón, T. Yildirim, J. F. Stoddart and O. K. Farha, Science, 2020, 368, 297-303.

$234 \mathrm{Y}$. He, W. Zhou and B. Chen, Current status of porous metal-organic frameworks for methane storage, Metal-Organic Frameworks: Applications in Separations and Catalysis, Wiley-VCH, 2018, pp. 163-198.

235 Z. R. Herm, E. D. Bloch and J. R. Long, Chem. Mater., 2014, 26, 323-338.

236 B. Li, H. Wang and B. Chen, Chem.-Asian J., 2014, 9, 1474-1498.

237 B. Van de Voorde, B. Bueken, J. Denayer and D. De Vos, Chem. Soc. Rev., 2014, 43, 5766-5788.

238 K. Adil, Y. Belmabkhout, R. S. Pillai, A. Cadiau, P. M. Bhatt, A. H. Assen, G. Maurin and M. Eddaoudi, Chem. Soc. Rev., 2017, 46, 3402-3430.

239 S. Mukherjee, A. V. Desai and S. K. Ghosh, Coord. Chem. Rev., 2018, 367, 82126.

240 H. Wang and J. Li, Acc. Chem. Res., 2019, 52, 1968-1978.

241 R.-B. Lin, S. Xiang, W. Zhou and B. Chen, Chem, 2020, 6, 337-363.

242 D. S. Sholl and R. P. Lively, Nature, 2016, 532, 435-437.

243 L. Li, Y. Wang, J. Yang, X. Wang and J. Li, J. Mater. Chem. A, 2015, 3, 2257422583.

244 L. Alaerts, M. Maes, L. Giebeler, P. A. Jacobs, J. A. Martens, J. F. M. Denayer, C. E. A. Kirschhock and D. E. De Vos, J. Am. Chem. Soc., 2008, 130, 1417014178.

245 V. Finsy, C. E. A. Kirschhock, G. Vedts, M. Maes, L. Alaerts, D. E. De Vos, G. V. Baron and J. F. M. Denayer, Chem.-Eur. J., 2009, 15, 7724-7731.

246 V. Bon, N. Kavoosi, I. Senkovska and S. Kaskel, ACS Appl. Mater. Interfaces, 2015, 7, 22292-22300.

247 J.-P. Zhang, P.-Q. Liao, H.-L. Zhou, R.-B. Lin and X.-M. Chen, Chem. Soc. Rev., 2014, 43, 5789-5814.

248 J. D. Evans, V. Bon, I. Senkovska, H.-C. Lee and S. Kaskel, Nat. Commun., 2020, 11, 2690.

249 T. D. Bennett, A. K. Cheetham, A. H. Fuchs and F.-X. Coudert, Nat. Chem., 2017, 9, 11-16.

250 X. Yang, H.-L. Zhou, C.-T. He, Z.-W. Mo, J.-W. Ye, X.-M. Chen and J.-P. Zhang, Research, 2019, 2019, 9463719. 
251 S. Ehrling, E. M. Reynolds, V. Bon, I. Senkovska, T. E. Gorelik, J. D. Evans, M. Rauche, M. Mendt, M. S. Weiss, A. Pöppl, E. Brunner, U. Kaiser, A. L. Goodwin and S. Kaskel, Nat. Chem., 2021, 13, 568-574.

252 S. Chibani and F.-X. Coudert, APL Mater., 2020, 8, 080701.

253 G. Fraux and F.-X. Coudert, Chem. Commun., 2017, 53, 7211-7221.

254 F.-X. Coudert, Phys. Chem. Chem. Phys., 2010, 12, 10904-10913.

255 F. J. Sotomayor and C. M. Lastoskie, Microporous Mesoporous Mater., 2020, 292, 109371.

256 S. Darwish, S.-Q. Wang, D. M. Croker, G. M. Walker and M. J. Zaworotko, ACS Sustainable Chem. Eng., 2019, 7, 19505-19512.

257 N. Stock and S. Biswas, Chem. Rev., 2012, 112, 933-969.

258 N. Chanut, A. Ghoufi, M.-V. Coulet, S. Bourrelly, B. Kuchta, G. Maurin and P. L. Llewellyn, Nat. Commun., 2020, 11, 1216.

259 J. Su, S. Yuan, H.-Y. Wang, L. Huang, J.-Y. Ge, E. Joseph, J. Qin, T. Cagin, J.-L. Zuo and H.-C. Zhou, Nat. Commun., 2017, 8, 1-8.

260 H. Li and M. R. Hill, Acc. Chem. Res., 2017, 50, 778-786.

261 C. Jones, A. Tansell and T. Easun, J. Mater. Chem. A, 2016, 4, 6714-6723. 